
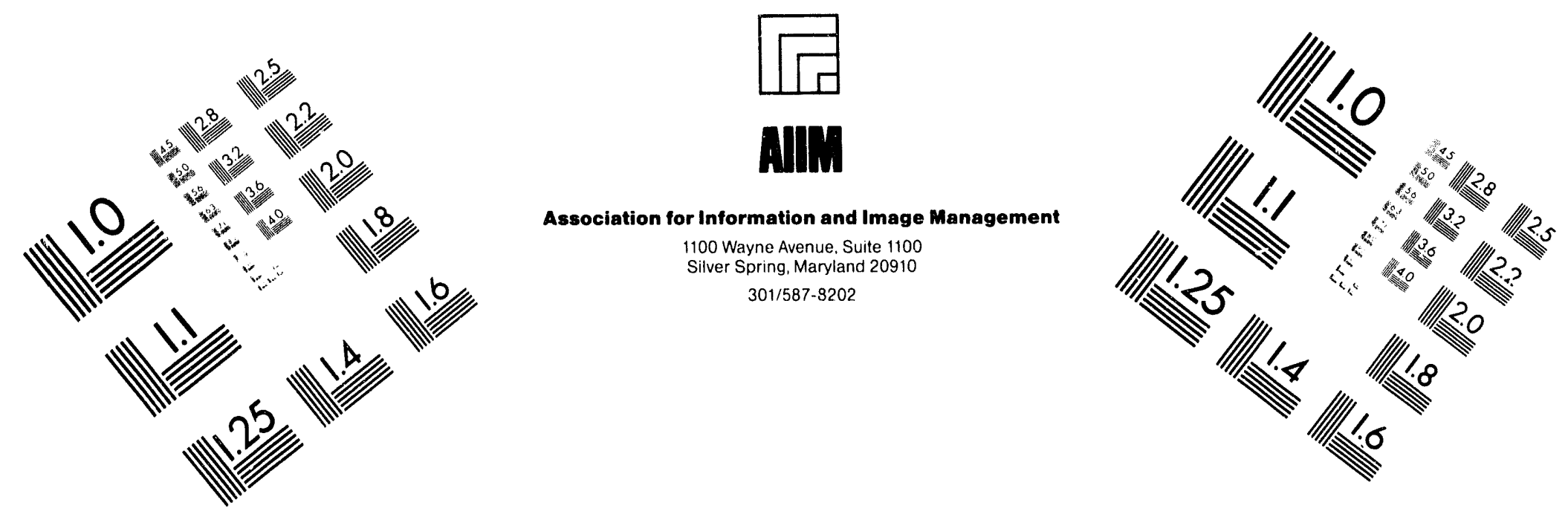

\title{
Centimeter
}

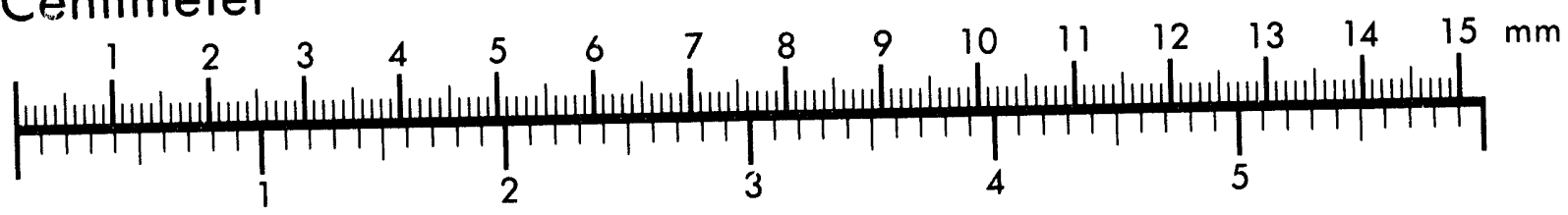
Inches
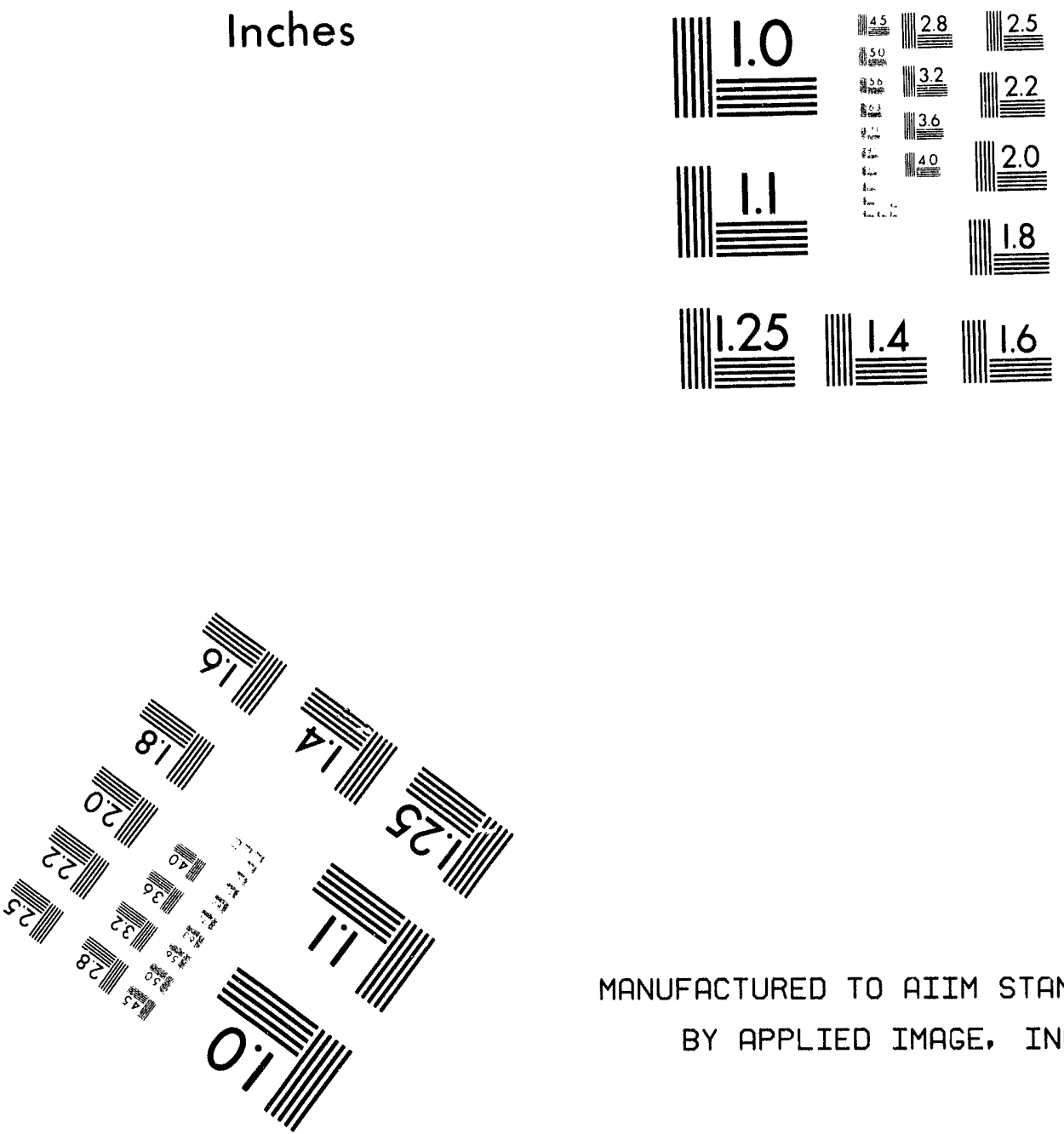

MANUFACTURED TO AIIM STANDARDS

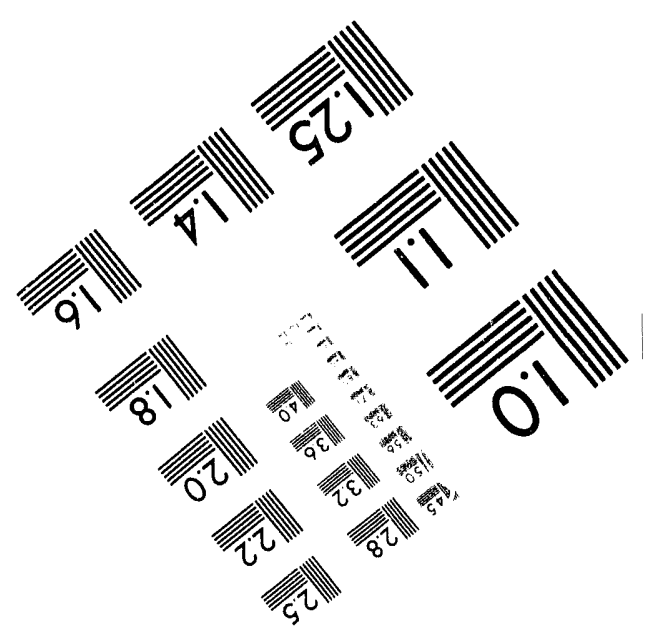



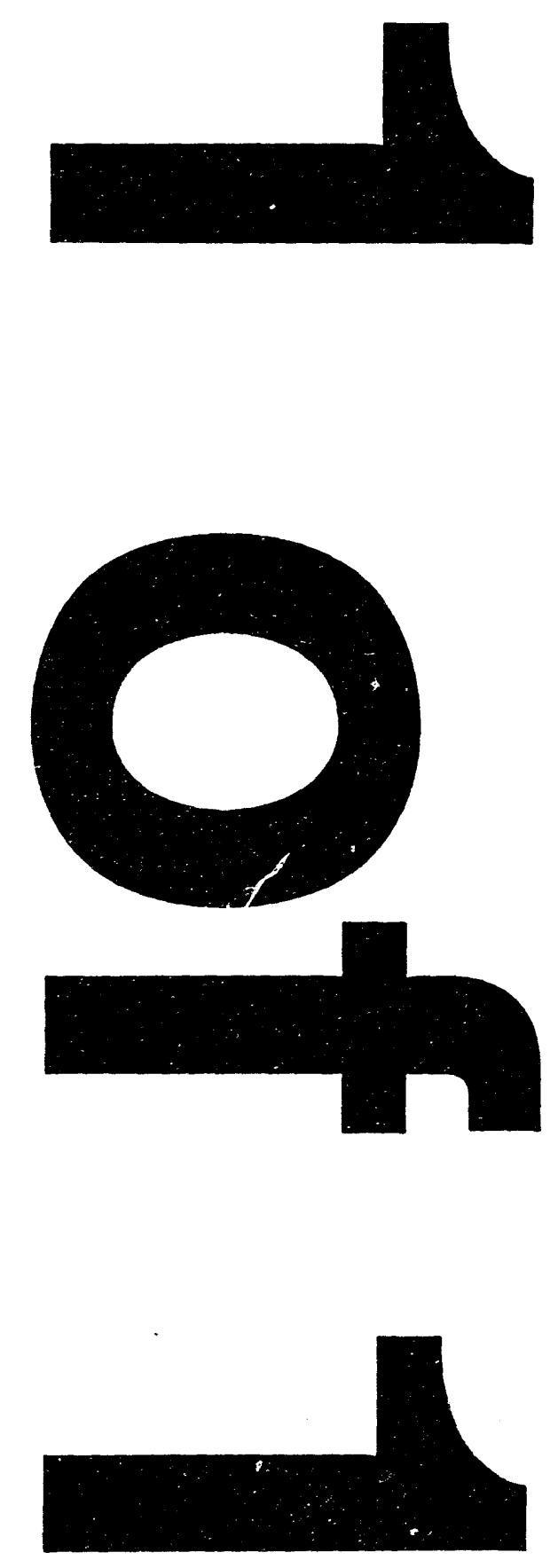


\title{
SEMICONDUCTOR ELECTROCHEMISTRY OF COAL PYRITE
}

\author{
Technical Progress Report
}

October - December 1993

by

\author{
K. Osseo-Asare and Dawei Wei \\ Department of Materials Science and Engineering \\ The Pennsylvania State University \\ University Park, PA 16802 \\ DISCLAIMER
}

\begin{abstract}
This report was prepared as an account of work sponsored by an agency of the United States Government. Neither the United States Government nor any agency thereof, nor any of their employees, makes any warranty, express or implied, or assumes any legal liability or responsibility for the accuracy, completeness, or usefulness of any information, apparatus, product, or process disclosed, or represents that its use would not infringe privately owned rights. Reference herein to any specific commercial product, process, or service by trade name, trademark, manufacturer, or otherwise does not necessarily constitute or imply its endorsement, recommendation, or favoring by 'he United States Government or any agency thereof. The views and opinions of authors expressed herein do not necessarily state or reflect those of the United States Government or any agency thereof.
\end{abstract}

\section{Prepared for the}

United States Department of Energy

\section{Under}

Grant No. DE-FG22-91 PC 91303

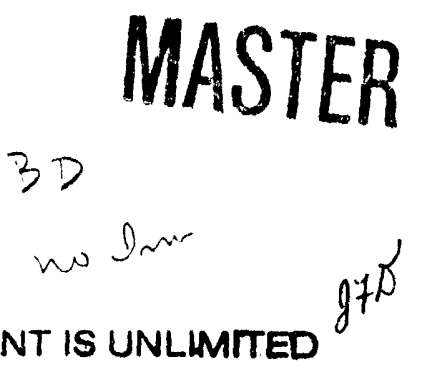




\title{
SEMICONDUCTOR ELECTROCHEMISTRY OF COAL PYRITE
}

\author{
Technical Progress Report \\ October - December 1993
}

\section{by}

K. Osseo-Asare and Dawei Wei

Department of Materials Science and Engineering

The Pennsylvania State University

University Park, PA 16802

March 1994 
TABLE OF CONTENTS

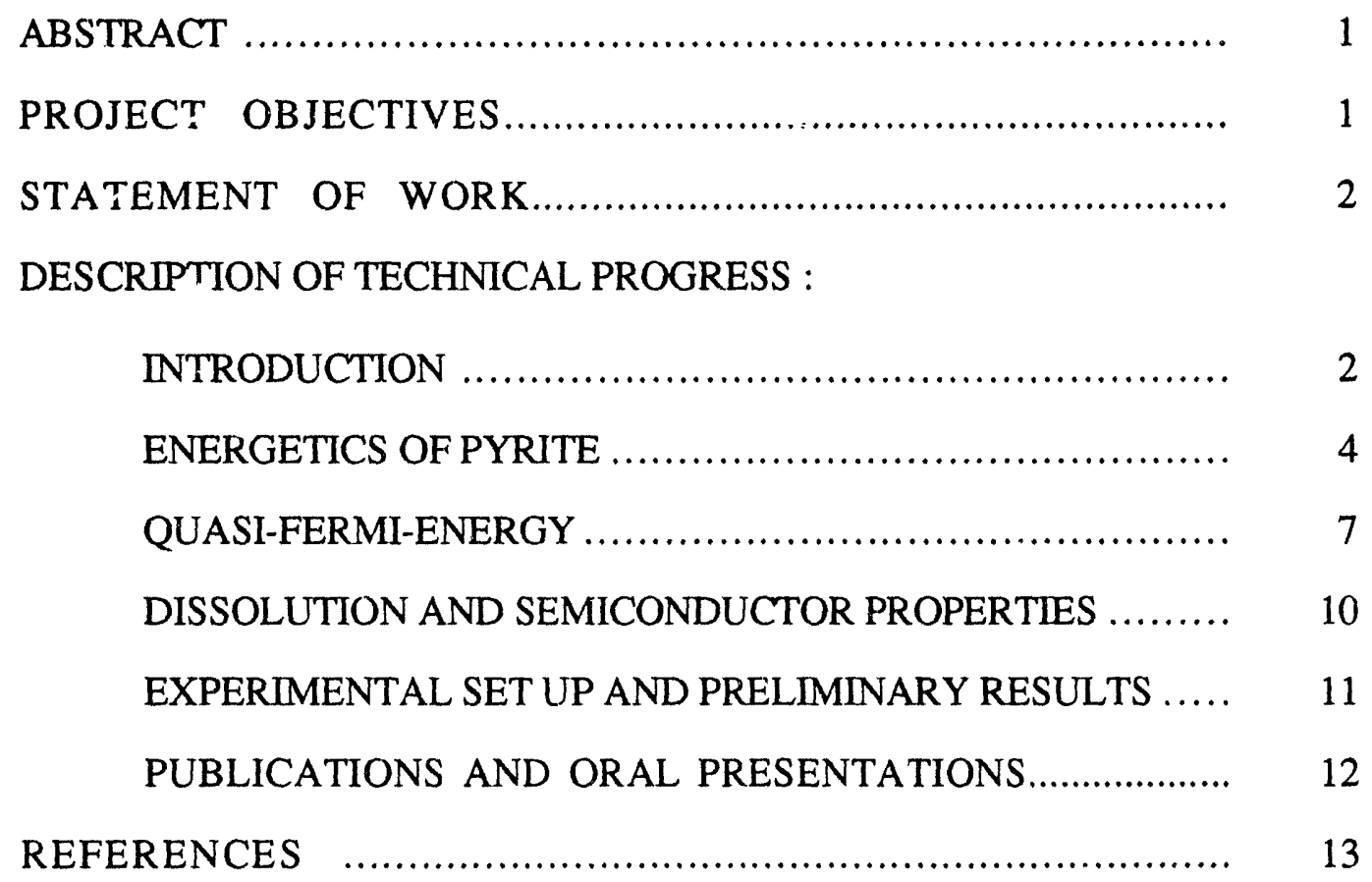




\begin{abstract}
The effects of the semiconductor properties of pyrite on its electrochemical behavior have been explored with the aid of energy level diagrams which illustrate the relationship between the energy levels of the solid and the equilibrium potentials of the redox couples in the aqueous solution. A novel approach to the study of pyrite electrochemistry was initiated. This approach is based on pyrite microelectrodes synthesized via aqueous phase precipitation. Preliminary results show that photocurrents can be generated by illumination of the pyrite particles synthesized in our laboratory.
\end{abstract}

\title{
PROJECT OBJECTIVES
}

This project seeks to advance the fundamental understanding of the physicochemical processes occurring at the pyrite/aqueous interface, in the context of coal cleaning, coal desulfurization, and acid mine drainage. A novel approach to the study of pyrite aqueous electrochemistry is proposed, based on the use of both synthetic and natural (i.e. coal-derived) pyrite specimens, the utilization of pyrite both in the form of micro (i.e. colloidal and subcolloidal) and macro (i.e. rotating ring disk) electrodes, and the application of in-situ direct electroanalytical and spectroele $₫$ ochemical characterization techniques. Central to this research is the recognition that pyrite is a semiconductor material. (Photo) eiectrochemical experiments will be conducted to unravel the mechanisms of anodic and cathodic processes such as those associated with pyrite decomposition and the reduction of oxidants such as molecular oxygen and the ferric ion. 


\section{STATEMENT OF WORK}

The experiments to be conducted fall into two main groups, depending on whether the pyrite specimens are used in the form of (a) nanoparticle microelectrodes, or (b) planar surface macroelectrodes. In the first case, synthetic pyrite microelectrodes will be used in the form of nanoparticles and the in-situ observation of the evolution of particle size and reaction products will be accomplished via photon correlation, absorption, and fluorescence spectroscopy techniques. In the second case, the experimental system will be based on a rotating ring disk electrode ( $R R C E)$ assembly, with coal pyrite serving as the disk and a $\mathrm{Pt}$ (or $\mathrm{Ag}, \mathrm{Cu}$ ) ring electrode permitting direct in-situ electroanalytical determination of reaction products.

\section{DESCRIPTION OF TECHNICAL PROGRESS}

\section{INTRODUCTION}

An understanding of the electrochemical properties of the pyrite-aqueous system is important for many aspects of advanced coal processing, e.g., coal cleaning, coal desulfurization, abatement of acid mine drainage. Pyrite is recognized as an electronic conductor and its oxidation has been described by the metal corrosion model for many years (Peters and Majima, 1968: Biegler and Swift, 1979, Peters, 1992). Pyrite is a semiconductor with a band gap $1 \pm 0.2 \mathrm{eV}$ (Marinace, 1954; Bither et al., 1968; Gupta et al., 1980; Ennaoui et al., 1986; Lin et al., 1988). However, some early investigators concluded that there was no significant relationship between the semiconductor properties of pyrite and the interfacial reactions of this metal sulfide. For example, it was reported that $\mathrm{n}$ - and $\mathrm{p}$ - type pyrite exhibited very similar anodic and cathodic polarization curves in acidic conditions. However, more recent electrochemical and photoelectrochemical 
experiments (Mishra and Osseo-Asare, 1987, 1988, 1992a) showed that the dissolution rate of pyrite increased in the presence of illumination, which means that both electrons and holes participate in the interfacial electrochemical reactions. Based on these and related observations, Osseo-Asare $(1992,1993)$ and Mishra and Osseo-Asare $(1988,1992 a, b)$ proposed a semiconductor dissolution model for pyrite. The semiconductor properties of pyrite are also important for solar energy conversion systems (Ennaoui et al., 1986; Tributsh, 1986; Chen et al., 1991), where photon energy is converted to electric or chemical energy, based on the electrochemical interactions at the semiconductor/aqueous interface.

Semiconductor dissolution processes may involve both electron and hole transfer routes. When the band gap of a semiconductor is larger than $\sim 0.66 \mathrm{eV}$, a hole transfer pathway will play a key role in the anodic dissolution process (Crundwell, 1988; OsseoAsare, 1992). The solid state properties of the semiconductor material, such as the bulk phase electronic structure, the band gap and band edges, the nature of surface states, the space charge region, and the quasi-Fermi-energy levels caused by illumination, will affect the dissolution rate. The interfacial electrochemical processes associated with the electron and hole transfers between the solid surface and the redox couples in the aqueous snlution will also influence the dissolution processes directly.

In this reporting period, the relationship between the energetics of pyrite and charge transfer with aqueous phase redox couples was explored with the aid of energy level diagrams (Osseo-Asare, 1993). The apparatus for the microelectrode-based photocurrent collection experiments was set up and preliminary experiments were conducted. In addition, two papers on the kinetics of formation of FeS were prepared and submitted for publication (Wei and Osseo-Asare 1993a,b). 


\section{ENERGETICS OF PYRITE}

Pyrite is a semiconductor with a band gap of about $1 \pm 0.2 \mathrm{eV}$. The band positions of pyrite in aqueous solution shift with the solution $\mathrm{pH}$ due to the adsorption of $\mathrm{H}^{+}, \mathrm{OH}^{-}$ and $\mathrm{SH}^{-}$ions on the particle surface. The $\mathrm{pH}$-dependent Fermi level of pyrite determined by Chen and co-workers (1991) is expressed as:

$$
\mathrm{E}_{\mathrm{F}}=0.18-0.059 \mathrm{pH}
$$

where $E_{F}$ is the Fermi level in terms of priential (Eh, V). For n-type pyrite, it can be assumed that the conduction band edge, $E_{C}$, is near the Fermi level, $E_{F}$, so that the band positions can be estimated by Equation 1 .

For the purpose of studying electrochemical reactions at the interface between a semiconductor solid and a liquid, it is useful to relate the energetics of the solid with the electrochemical potentials of the redox couples in solution. Conventionally, the energy levels are expressed in units of electron volts $(\mathrm{eV})$, which take the energy of a free electron at infinity as the reference. On the other hand, the redox couples are characterized conventionally by electrochemical potentials (V); the reference state may be taken as the potential of either the standard hydrogen eiectrode (SHE) or the saturated calomel electrode (SCE). The relationship between the energy level $(\mathrm{E}, \mathrm{eV})$ and the electrochemical potential (Eh,V), taking SHE as reference, is given by (Morrison 1980; and Osseo-Asare, 1992):

$$
E(e V)=-e E h(V)-45
$$

Based on Equations 1 and 2, the energy level diagram of pyrite can be constructed (OsseoAsare, 1993) as shown in Figure 1, where $E_{V}$ and $E_{C}$ refer to the bottom of the conduction band and the top of the valence band respectively. 
The energy level diagrams of semiconductor materials are very useful for examining the reaction mechanisms involved in the reaction systems. For example, the band gap $\left(E_{g}\right)$ of $1 \mathrm{eV}$ for pyrite indicates that visible light, which has energies from $1.7 \mathrm{eV}$ to $3.1 \mathrm{eV}$, can excite electrons from the valence band to the conduction band, leaving holes in the valence band. There are at least three possible ways for the electron-hole pairs to react further, as shown in Figure 2: (a) the electrons excited may recombine with the holes; (b) the electron-hole pairs may interact with species in the aqueous solution; and (c) the holes may oxidize the lattice atoms of the solid.

The electron-hole pairs can react with the aqueous species in different ways, depending on the relative energetics of the solid and the aqueous phases. The electrochemical potential of a redox couple in solution may be located in various positions around the band gap of a semiconductor, as shown in Figure 3. These various positions result in different electrochemical reactions between the semiconductor and the aqueous species. Thus, if the electrochemical potential of a redox couple is above the conduction band edge, the aqueous species cannot react with the elcctrons in the conduction band (cb), but can react with the holes in the valence band (vb):

$$
\mathrm{R}+\mathrm{h}^{+}(\mathrm{vb})-->\mathrm{O}
$$

When the Eh of the redox couple lies between $E_{c}$ and $E_{v}$, both the electrons in the conduction band and the holes in the valence band may react with the aqueous species:

or

$$
\mathrm{O}^{\prime}+\mathrm{e}^{-}(\mathrm{cb})-->\mathrm{R}^{\prime}
$$

$$
\mathrm{R}^{\prime}+\mathrm{h}^{+}(\mathrm{vb})->\mathrm{O}^{\prime}
$$


In the case where the Eh of the redox couple lies below the valence band edge, the holes in the valence band cannot react with the redox couple, but the electrons in the conduction band can react with the aqueous species:

$$
\mathrm{O}^{\prime \prime}+\mathrm{e}^{-}(\mathrm{cb})-\cdots>\mathrm{R}^{\prime \prime}
$$

or the aqueous species may react with the electrons in the valence band and inject holes in the band:

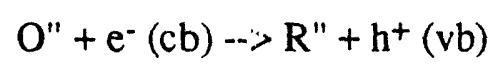

Since the band nositions of pyrite depend on the solution $\mathrm{pH}$ (Equation 1), but the electrochemical potentials of some redox couples do not, the relative locations of the band edges of the solid bands and potentials of the redox couples may change with $\mathrm{pH}$. The relationship between the energetics of pyrite and the redox couples $\mathrm{MV}^{2+} / \mathrm{MV}^{+}+(\mathrm{MV}=$ methylviolog a) and $\mathrm{Fe}^{3+} / \mathrm{Fe}^{2+}$ is shown as a function of $\mathrm{pH}$ in Figure 4 . It can be seen that at $\mathrm{pH}$ less than 10.7 , the $\mathrm{MV}^{2+} / \mathrm{MV}^{++}$couple cannot react with the electrons in the conduction band because their redox potential $(-0.45 \mathrm{~V})$ lies above $\mathrm{E}_{\mathrm{c}}$. However, at $\mathrm{pH}$ larger than 10.7, $\mathrm{MV}^{2+}$ will react with the electrons in the conduction band to form the radical $\mathrm{MV}^{\cdot+(}$ (Chen et al., 1991). Figure 5 compares the band edges of pyrite with the energy levels of several redox couples (Osseo-Asare, 1993). It can be seen that the corresponding oxidants can be divided into two groups, i.e., those which are most likely to accept conduction band electrons $\left(\mathrm{E}_{\mathrm{Tedox}}(\mathrm{V})<\mathrm{E}_{\mathrm{V}}: \mathrm{O}_{2}, \mathrm{Fe}^{3+}, \mathrm{HNO}_{3}\right)$ and those which are most likely to inject holes into the valence band $\left(\mathrm{E}_{\mathrm{xedox}}(\mathrm{V})>\mathrm{E}_{\mathrm{v}}: \mathrm{H}_{2} \mathrm{O}_{2}, \mathrm{Cl}_{2}\right)$.

Our previous electroreduction investigations (Mishra and Osseo-Asare, 1992b) focused on the conduction band reactants, i.e., $\mathrm{O}_{2}, \mathrm{Fe}^{3+}$. In future work, we plan to extend our work to the valence band reactants. 


\section{QUASI-FERMI ENERGY}

For the electron transfer between solids and aqueous species, the electrochemical potential of the electrons in the solid must be equal to that in the solution when the solid and the aqueous species are in equilibrium (Crundwell, 1988; Osseo-Asare, 1992). That is, the Fermi energy of the solid must be equal to the equilibrium potential of the redox couple in the solution:

$$
\mathrm{E}_{\mathrm{F}}=\mathrm{E}^{\mathrm{eq}} \mathrm{redox}
$$

The Fermi level is located in different positions for different semiconductor materials, as shown in Figure 6. For an intrinsic semiconductor at room temperature, if we assume that the mass of the electron near the bottom of the conduction band is equal to the mass of holes near the top of the valence band, the Fermi level may lie essentially midway between the conduction band and the valence band, within the band gap. For n-type, semiconductors, $E_{F}$ lies slightly below the conduction band, while for p-type semiconductors, $E_{F}$ lies just above the valence band (Bard and Faulkner, 1980).

However, when a semiconducior is illiminated by a light with an energy greater than its band gap, the electrons will be excited into the conduction band and the holes are created in the valence band, leading to an excess of both carriers of electrons and holes. Considering that $\mathrm{n}_{0}$ and $\mathrm{p}_{0}$ are the equilibrium concentrations of electrons in the conduction band and of holes in the valence band respectively, and $\Delta \mathrm{n}$ and $\Delta \mathrm{p}$ are the excess concentrations generated by illumination, the change in free energy associated with illumination can be expressed as (Gerischer, 1966; Ward et al., 1983):

$$
\Delta \mu_{\mathrm{e}}={ }_{\mathrm{n}} E_{\mathrm{F}}-E_{\mathrm{F}}=k T \ln \left(1+\Delta \mathrm{n} / \mathrm{n}_{\mathrm{O}}\right)
$$




$$
\Delta \mu_{p}={ }_{p} E_{F}-E_{F}=-k T \ln \left(1+\Delta p / p_{0}\right)
$$

where ${ }_{n} \mathrm{E}_{\mathrm{F}}$ and ${ }_{\mathrm{p}} \mathrm{E}_{\mathrm{F}}$ are defined as quasi-Fermi energies, which describe the concentration of the electrons in the conduction band and of holes in the valence band respectively at non equilibrium conditions.

At thermodynamic equilibrium, the Fermi energy is in the center of the band gap for an intrinsic semiconductor as shown in Figure 6. If $\left(E_{c}-E_{F}\right)$ or $\left(E_{F}-E_{v}\right)$ exceeds $2 k T$, the Fermi -Dirac function can be simplified and we have:

$$
\mathrm{n}_{\mathrm{o}}=\mathrm{N}_{\mathrm{c}} \exp \left[-\left(\mathrm{E}_{\mathrm{c}}-\mathrm{E}_{\mathrm{F}}\right) / \mathrm{kT}\right]
$$

and

$$
\mathrm{p}_{\mathrm{o}}=\mathrm{N}_{\mathrm{v}} \exp \left[-\left(\mathrm{E}_{\mathrm{F}}-\mathrm{E}_{\mathrm{v}}\right) / \mathrm{kT}\right]
$$

where $N_{c}$ and $N_{v}$ are the effective densities of energy levels in the conduction and valence bands respectively. Thus we obtain:

$$
n_{\mathrm{o}} p_{0}=N_{c} N_{v} \exp \left(-E_{g} / k T\right)
$$

where $E_{g}$ is the band gap, $E_{g}=E_{c}-E_{v}$.

Equation 13 shows that ior a given semiconductor at equilibrium, $\mathrm{n}_{\mathrm{o}}$ and $\mathrm{p}_{\mathrm{o}}$ cannot both be large; if one is large, the other must be small. Hence, it can be seen from Equations 9 and 10 that the change in free energy :nder illumination is much greater for minority carriers than for majority carriers. In other words, the concentration of majority carriers is not appreciably increased by illumination, so the quasi-Fermi energy for majority carriers is almost the same as the equilibrium Fermi energy. However, the quasi-Fermi energy for the minority carriers can be changed substantially. For example, an n-type semiconductor has electrons as majority carriers and holes as minority carriers with the equilibrium Fermi 
energy near the conduction band. Under illumination, the concentration of the holes may increase many orders of magnitude, so that ${ }_{\mathrm{p}} \mathrm{E}_{\mathrm{F}}$ will decrease dramatically. In fact, ${ }_{\mathrm{p}} \mathrm{E}_{\mathrm{F}}$ may be very near the valence band of the semiconductor. However, the effect of illumination on electron concentration is not much for an n-type semiconductor, thus ${ }_{n} E_{F}$ increases a little and is still located near the conduction band. The quasi-Fermi energies for intrinsic, n-type and p-type semiconductors are illustrated in Figure 7.

The concept of quasi-Fermi energy is very important in the electrochemical studies of semiconductors. An enormous electrochemical effect may be caused by this large deviation from equilibrium for the minority carriers, especially when we are interested in the reaction of minority carriers with species in solution, while the effect due to the variation of majority carriers will have negligible importance.

As discussed earlier, the concentrations of carriers initially present, $\mathrm{n}_{\mathrm{o}}$ and $\mathrm{p}_{\mathrm{o}}$, depend on the band gap of the semiconductor. However, the magnitudes of excess carriers generated by illumination, $\Delta \mathrm{n}$ and $\Delta \mathrm{p}$, are dependent upon the intensity of the illumination, the recombination rate of electrons and holes, and the rates of electron or hole transfer to aqueous species (Ward et al., 1983). If we assume that $\Delta \mathrm{n}$ is proportional to the light intensity and $\left(\Delta n / n_{0}\right) \gg>1$, then it follows from Equation 9 that:

$$
{ }_{n} E_{F}=\text { Constant }+k T \ln (I)
$$

Thus an increase of the light intensity will result in an increase of $\Delta \mathrm{n}$ and a rise of ${ }_{n} E_{F}$. On the other hand, an increase of the light intensity will shift $\mathrm{p}_{\mathrm{F}}$ to a lower value.

Some consequences of these ideas are illustrated in Figure 8, where the energy levels of pyrite at $\mathrm{pH} 0$ are compared with the standard potentials of two redox couples in solution; $\mathrm{E}^{\mathrm{O}} \mathrm{Pd}$ and $\mathrm{E}^{\circ} \mathrm{Cu}$ are taken as the equilibrium potentials for reactions 15 and 16 respectively. When pyrite is absent from the solution, reaction 16 will go to the left, while reaction 15 will go to the right, because $\mathrm{E}^{0} \mathrm{Pd}>\mathrm{E}^{0} \mathrm{Cu}$. That is, the formation of $\mathrm{Cu}^{2+}$ and 
Pd will be spontaneous. When the redox couples come into contact with the semiconductor, the electrons in the conduction band will reduce $\mathrm{Pd}^{2+}$ to form $\mathrm{Pd}$, and the holes in the valence band will oxidize $\mathrm{Cu}$ to form $\mathrm{Cu}^{2+}$, because $\mathrm{E}_{\mathrm{F}}>\mathrm{E}^{0} \mathrm{Pd}$ and $\mathrm{E}_{\mathrm{F}}<\mathrm{E}^{\circ} \mathrm{Cu}$. Therefore, the whole process is thermodynamically spontaneous. However, the Fermi energy in pyrite will be split into ${ }_{n} E_{F}$ and ${ }_{p} E_{F}$ under illumination as discussed above. If one assumes that under illumination, ${ }_{n} E_{F}>E^{\circ} \mathrm{Cu}$ and ${ }_{p} E_{F}<E^{0}{ }_{P d}$, the electrons in the conduction band may reduce $\mathrm{Cu}^{2+}$ to form $\mathrm{Cu}$ and the holes in the valence band may oxidize Pd to form $\mathrm{Pd}^{2+}$, as shown in Figure 9. Such a process is not thermodynamically spontaneous, but the reactions can proceed in the directions shown in Equations 17 and 18 as a result of catalysis by the semiconductor under illumination.

\section{DISSOLUTION AND SEMICONDUCTOR PROPERTIES}

As shown in Figure 10, when a photoelectrochemical cell is designed such that no hole acceptor is present in the solution, and the electrons excited in the conduction band can be scavenged by an aqueous species, the holes in the valence band will react with the lattice atoms. If the electrons can be transferred from the electron acceptor to an electrode, the anodic current will be proportional to the rate of the oxidation or dissolution of the semiconductors. In order to be effective as an electron acceptor, the aqueous species must be carefully selected. The potential of the redox couple should larger than $E_{c}$ in order to accept the electrons from the conduction band, and smaller than the potential on the electrode so that the electrons can be collected on the electrode. Two other issues are also very important: the electrons must not recombine with the holes and the holes must not react with the aqueous species when it has been reduced by the electrons. These can be achieved by selecting the redox couple which can accept the electrons in the conduction band much fast than the rate of electron hole recombination, and the rate of electron transfer to electrode from the reduced species should be much faster than that to the holes. The possible reactions can be summarized as: 


$$
\begin{aligned}
& \text { O(aqueous) }+\mathrm{e}^{-}(\mathrm{cb})-->\mathrm{R} \text { (aqueous) } \\
& \mathrm{R} \text { (aqueous) }->\mathrm{O}(\text { aqueous })+\mathrm{e}^{-} \text {(electrode) } \\
& \mathrm{R}(\text { lattice })+\mathrm{h}^{+}(\mathrm{vb})-->\mathrm{O}(\text { lattice }) \\
& \mathrm{R} \text { (aqueous) }+\mathrm{h}^{+}(\mathrm{vb})-->\mathrm{O} \text { (aqueous) } \\
& \mathrm{e}(\mathrm{cb})+\mathrm{h}^{+}-->\text {recombination }
\end{aligned}
$$

Where it is desired to study the dissolution of the semiconductor, the reactions described by Equations 22 and 23 must be inhibited.

The dissolution of a semiconductor such as pyrite is further complicated by the fact that irradiation excites the non-bonding electrons in the iron $t_{2 g}$ orbital in the valence band to the $\mathrm{eg}^{*}$ orbital in the conduction band (Osseo-Asare, 1992; Tributsch, 1986). The resulting oxidation of the lattice $\mathrm{Fe}$ atoms by the holes (Equation 24) will not directly lead to bond breakage.

$$
\mathrm{Fe}^{2+}+\mathrm{h}->\mathrm{Fe}^{3+}
$$

The transportation of the holes from iron ions to sulfide ions through an $\mathrm{OH}$. radical intermediate has been suggested (Mishra and Osseo-Asare (1988, 1992); Tributsch, 196).

\section{EXPERIMENTAL SET UP AND PRELIMINARY RESULTS}

The apparatus used in the electrochemical and photoelectrochemical is shown in Figure 11. The $100 \mathrm{ml}$ Pyrex H-cell consists of two chambers separated by a fine porosity glass frit, as used by Ward et al.(1983), so that the pyrite particles are confined to the main chamber. A platinum grid working electrode with area of $5 \mathrm{~cm}^{2}$ and a saturated calomel reference electrode (SCE) are in the main chamber and a platinum grid counter electrode is in the other chamber. On the wall of the main chamber there is a flat window which allows 
the light go into the cell directly. The light source is an Oriel $250 \mathrm{~W}$ halogen lamp. A water bath with $14 \mathrm{~cm}$ length is placed between the cell to absorb the heat. A model 273 Potentiostat /Galvanostat (EG\&G Princeton Applied Research) with a model 352 corrosion analysis software was used to make the electrochemical measurements.

A typical current-time curve is shown in Figure 12 under the conditions of $1 \mathrm{M}$ $\mathrm{NaS}_{2}, \mathrm{pH} 13.0$, and $70 \mathrm{mg} \mathrm{FeS} 2(\sim 2 \mu \mathrm{m}$ in diameter). Prepurified nitrogen stream was bubbled through the cell and a magnetic stirrer was used in the main chamber during the measurements. The working electrode was held at a potential at $-0.67 \mathrm{~V}(\mathrm{SCE})$. It can be seen that illumination can enhance the anodic current dramatically. The enhanced current results from the conduction band electrons generated under illumination because illumination does not change the anodic current in the absence of the pyrite particles.

\section{PUBLICATIONS AND ORAL PRESENTATIONS}

A Keynote Paper entitled, "Pyrite in Aqueous Systems: Semicondurtor Properties, Oxidative Dissolution, and Environmental Control" (Osseo-Asare, 1993) was presented in the Environmental Control Session of the First International Symposium on Processing Materials for Properties (Honolulu, Hawaii, November, 1993). A reprint of this paper is attached.

There are indications that surface states attributable to FeS play a critical role in the interfacial electrochemistry of pyrite (Mishra and Osseo-Asare, 1992 b; Alonso-Vante et al., 1988). Also FeS is reported to be an intermediate in the formation of pyrite (Morse et al., 1987). Two papers on the kinetics of formation of FeS were prepared and submitted to journals (Wei and Osseo-Asare, $1993 \mathrm{a}, \mathrm{b}$ ). Abstracts of these papers are attached. 


\section{REFERENCES}

Alonso-Vante et al., 1988. Solar Energy Mater., 18:9.

Bard A. J., and Faulkner L. R., 1980. Electrochemical Method,, John Wiley \& Sons., New York, p. 633.

Biegler, T., 1975. J. Electroanal. Chem., 70:265-275.

Biegler, T., and Swift, D. A., 1979. Electrochimica Acta 24:415-420.

Bither T, A., Bouchard R. J., Cloud W. H., Donohue P. C., and Siemons W., 1968. Inorg. Chem., 7:2208.

Chen, G., Zen, J. M., Fan, F. R. F., and Bard, A. J., 1991. J. Phys. Chem., 95:3682-3687.

Crundwell, F. K., 1988. Hydrometallurgy, 21:155-190.

Ennaoui, A., Fiechter, S., Jaegermann, W., and Tributsch, H., 1986. J. Elecrochem. Soc., 133:97-106.

Gerischer H., 1966. J. Electrochem. Soc., 113: 1174-1182.

Gupta V. P., Ravindra N. M., and Srirastava V. K., 1980. J. Phys. Chem. Solids, 41:145.

Liu C. Y., Pettenkofer C., Tributsch H., 1988. Surf. Sci., 204:537.

Marinace J. C., 1954. Phys. Rev., 96:593.

Mishra, K. K., and Osseo-Asare, K., 1987. Fuel, 66:1161-1162.

Mishra, K. K., and Osseo-Asare, K., 1988. J. Electrochem. Soc., 135:2502-2509.

Mishra, K. K., and Osseo-Asare, K., 1992a. J. Electrochem. Soc., 139:749-752.

Mishra, K. K., and Osseo-Asare, K., 1992b. J. Electrochem. Soc., 139:3116-3120.

Morrison S. R., 1980. Electrochemistry at Semiconductor and Oxidized Metal Electrodes, Plenum, New York, pp.5-8.

Morse, J. W., Millero, F. J., Cornwell, J. C., and Rickard, D., 1987. Earth Sci. Rev., $24: 1-42$.

Osseo-Asare, K., 1992. Hydrometallurgy, 29:61-90.

Osseo-Asare, K., 1993. 1st Int. Cong. Processing Materials for Properties. H. Henein and T. Oki, eds., The Minerals, Metals and Materials Soc., pp.83-89. 
Peters, E., 1992. Hydrometallurgy, 29:431-457.

Peters, E., and Majima, H., 1968. Can. Metall. Q., 7(3):111-117.

Springer, G., 1970. Trans. Inst. Min. Metall., Sect. C., 79:C11-C14.

Tributsch, H., 1986. J. O'M. Bockris, B. E. Conway and R. E. White, eds., Plenum, New York, Vol. 17, pp.303-355.

Vijh A. K., 1973. Electrochemistry of Mietals and Suiniconductors, Marcel Dekker, New York, p. 6.

Ward M. D., White J. R., and Bard A. J., 1983. J. Am. Chem. Soc., 105: $27-31$.

Wei, D., and Osseo-Asare, K., 1993a, "Formation of Iron Monosulfide in Aqueous Solution: A Spectrophotometric Study of the Reaction between Ferrous and Sulfide Ions", J. Colloid Interface Sci., submitted.

Wei, D., and Osseo-Asare, K., 1993b, "A Kinetic and Thermodynamic Study of the Reaction between Ferrous and Sulfide Ions in Aqueous Solutions", Geochimica Cosmochimica Acta, submitted. 


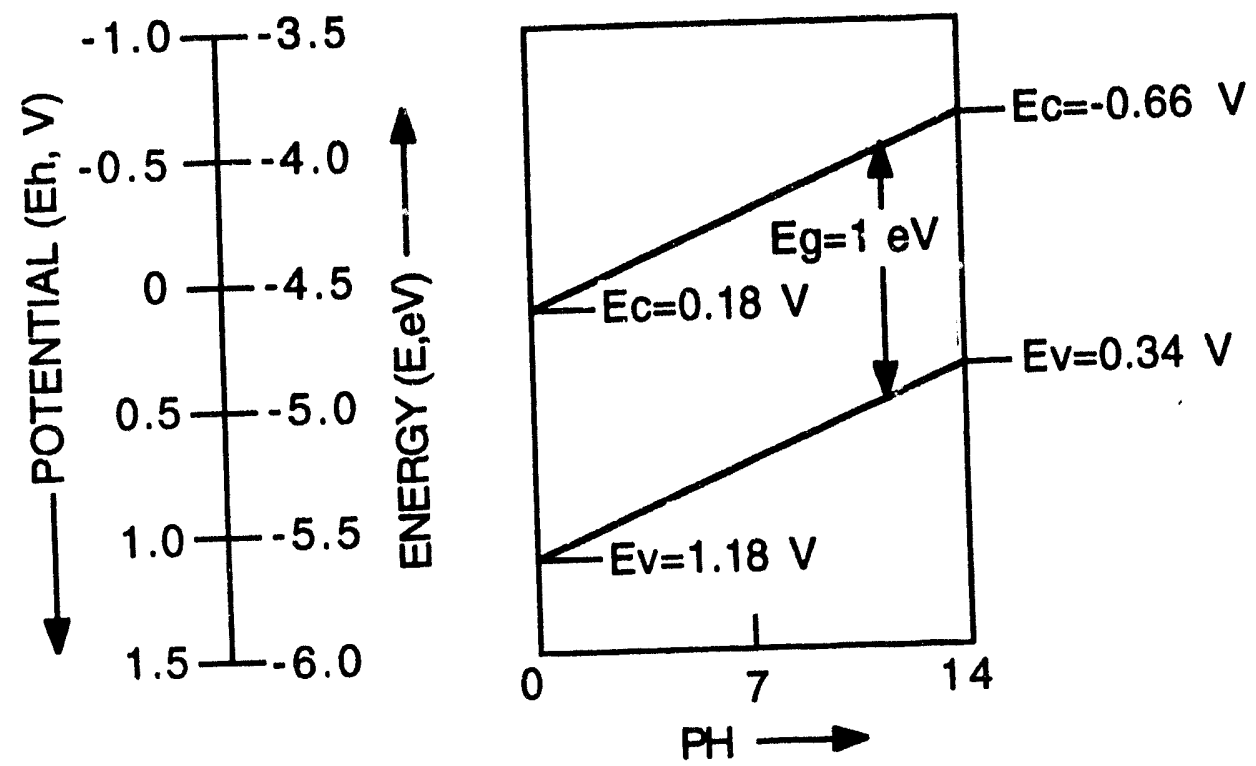

FIGURE 1. Energy diagram of semiconductor pyrite.

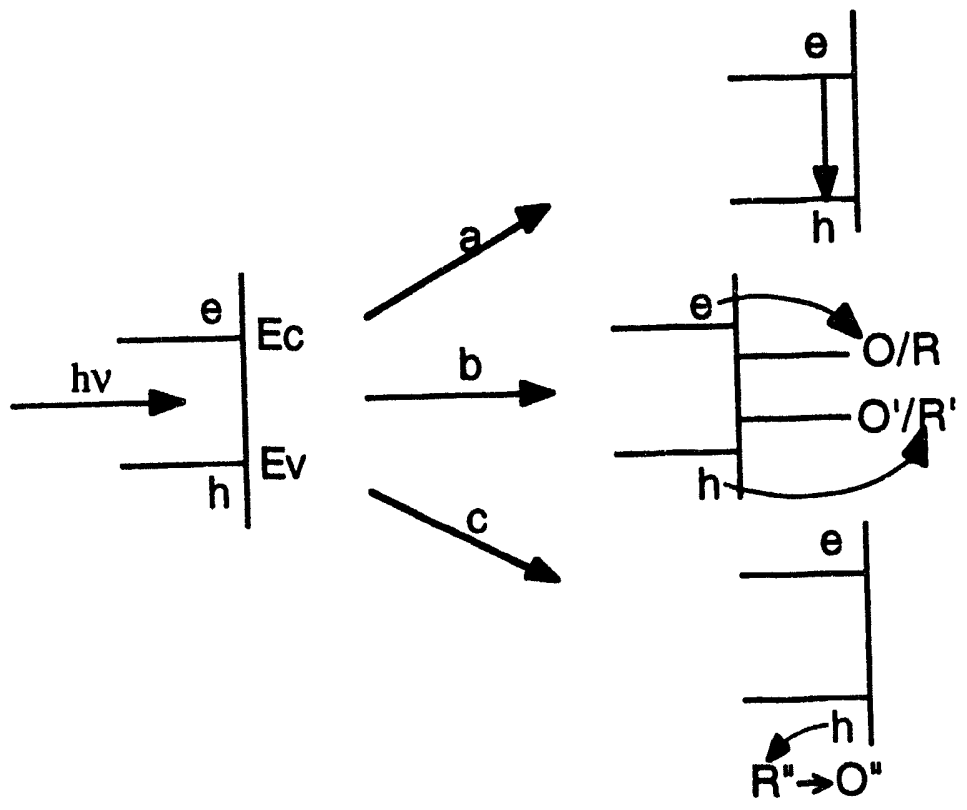

FIGURE 2. Reactions of electrons in CB and holes in CB with envorinments. 


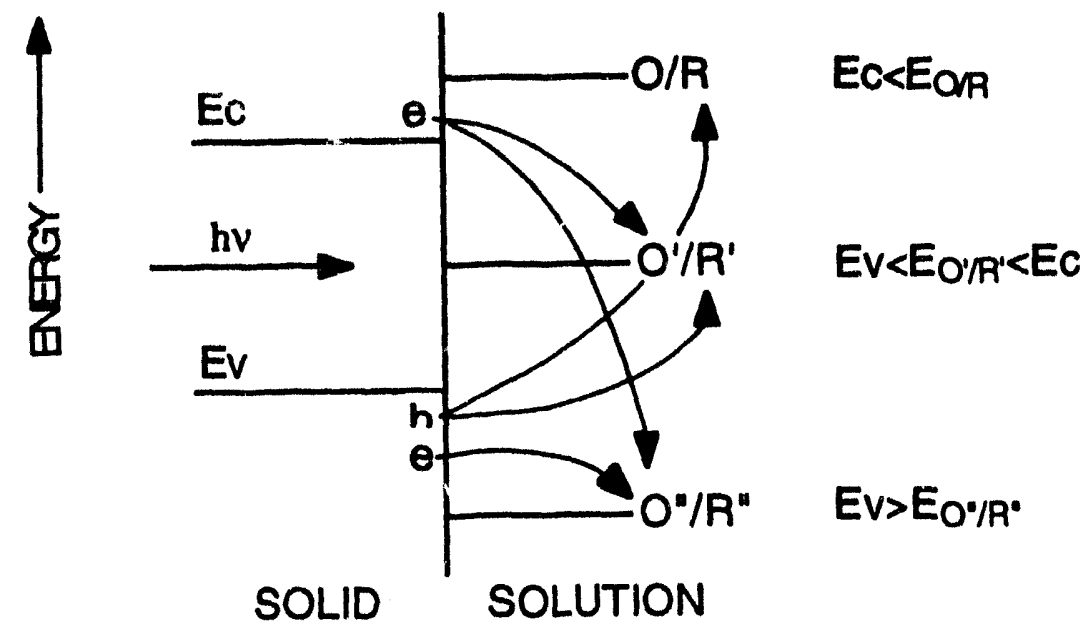

FIGURE 3. Reactions between electron-hole pairs and aqueous redox couples.

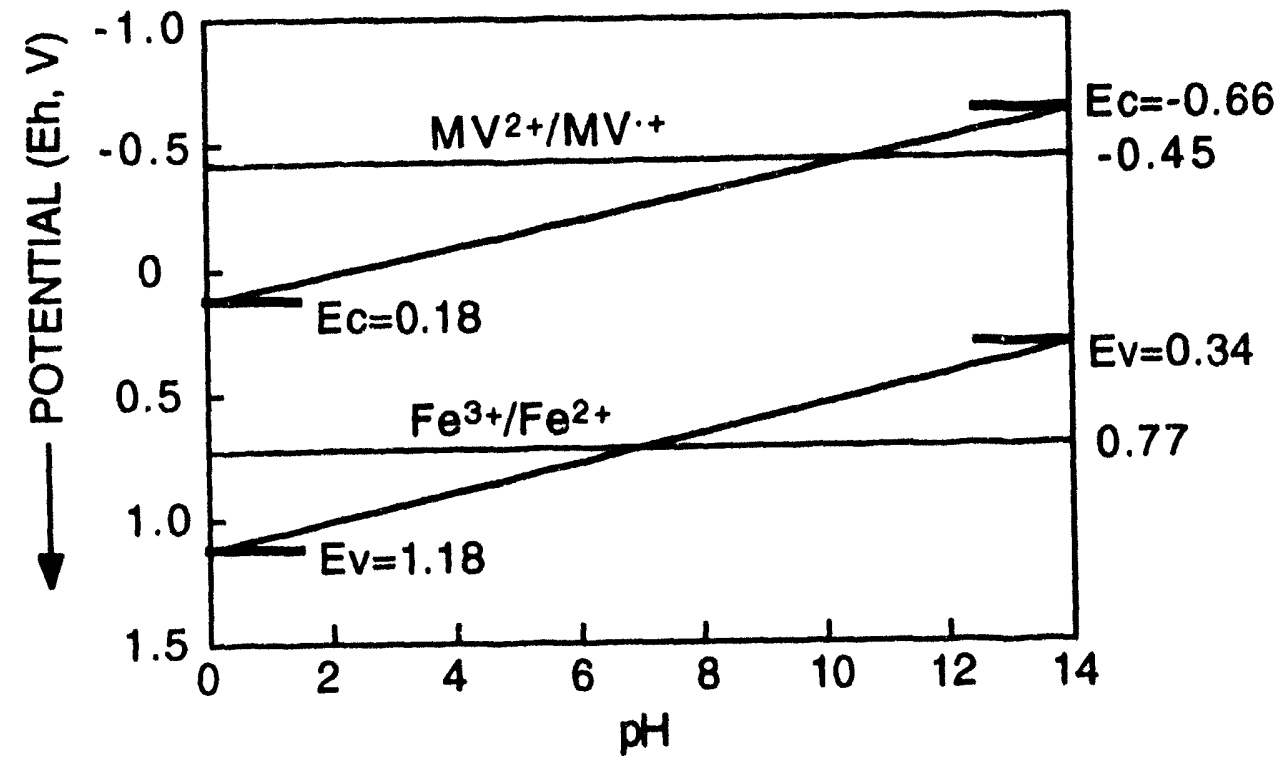

FIGURE 4. Relative potentials between the bands of pyrite and redox couples as a function of $\mathrm{pH}$. 


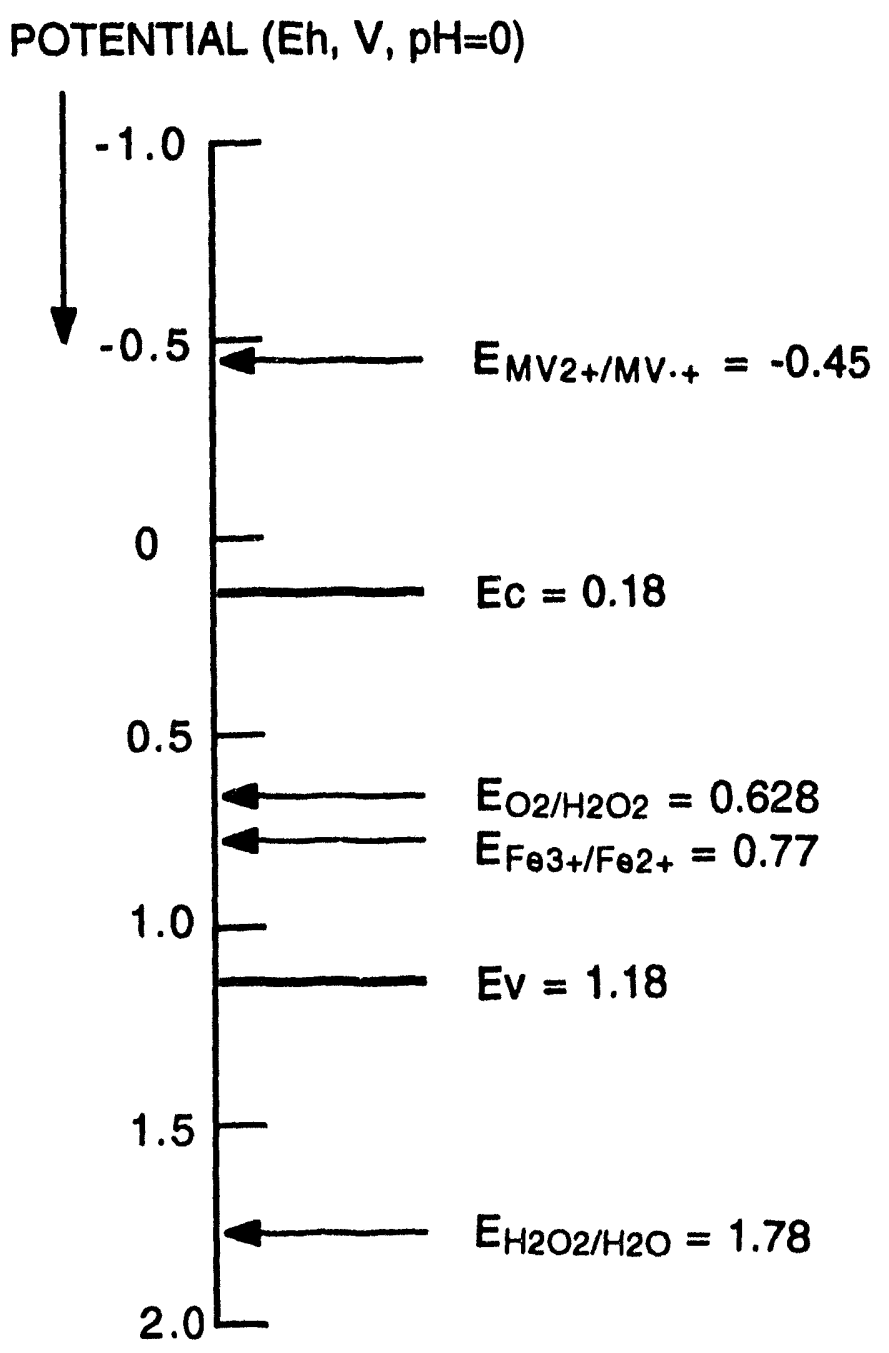

FIGURE 5. Energetics of pyrite with potentials of redox couples in solution. 


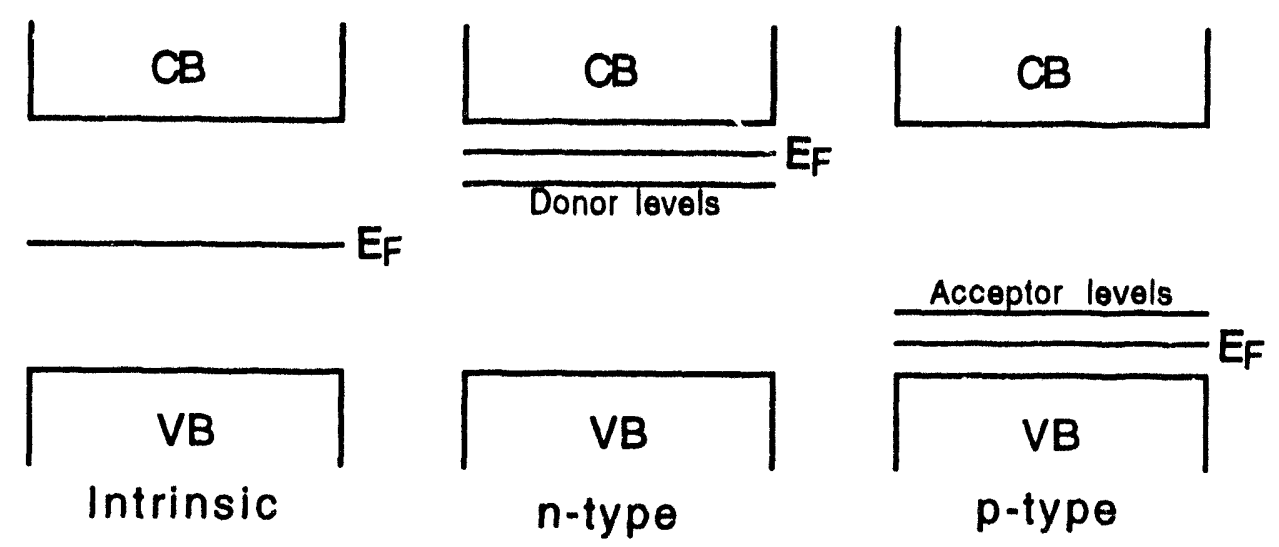

FIGL'RE 6. Fermi energy levels for different semiconductors.

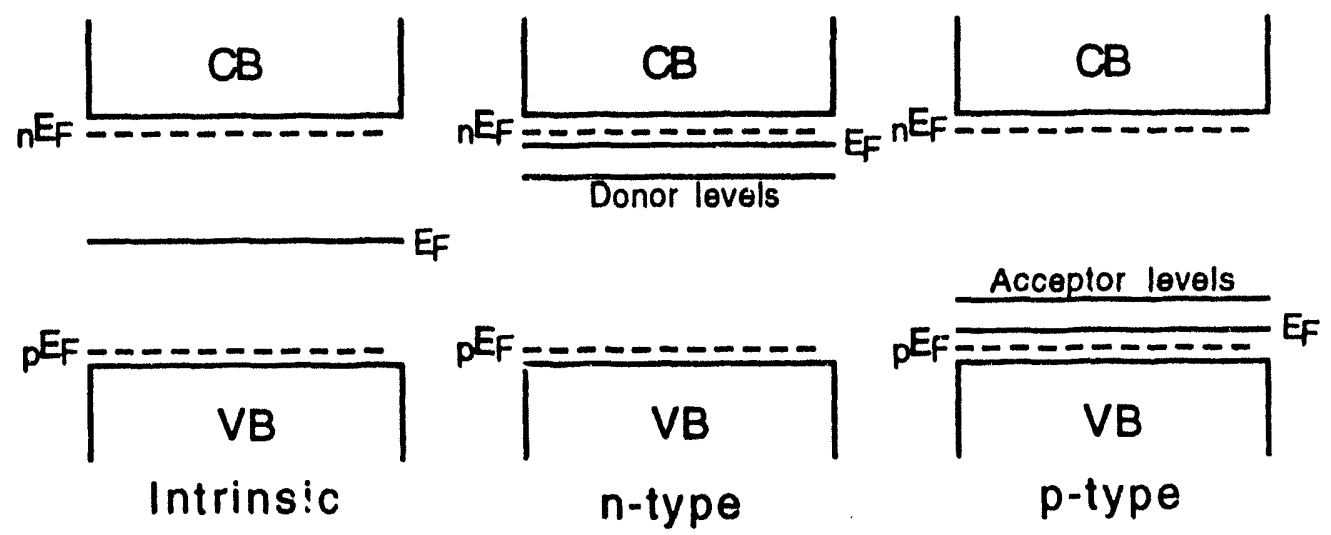

FIGURE 7. Quasi-Fermi energy levels for different semiconductors under illumination. 


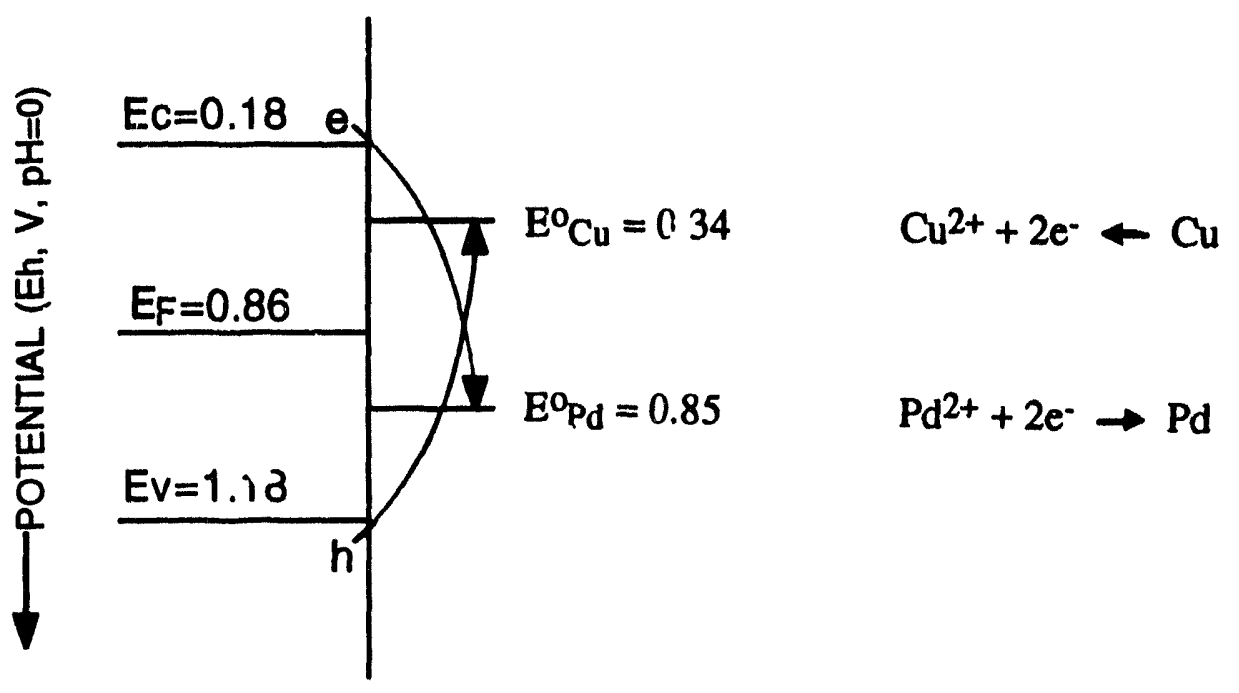

FIGURE 8. Redox reactions in $\mathrm{FeS}_{2}-\mathrm{Cu}$-Pd system without illumination.

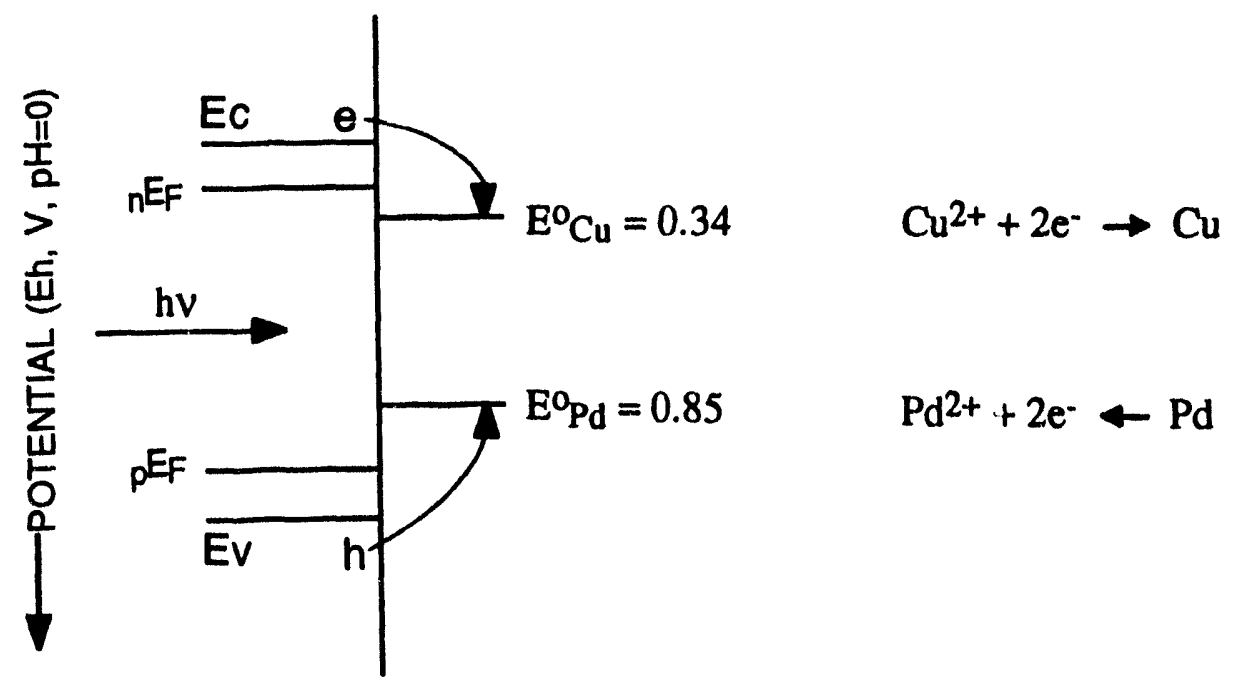

FIGURE 9. Redox reactions in $\mathrm{FeS}_{2}$-Cu-Pd system with illumination. 


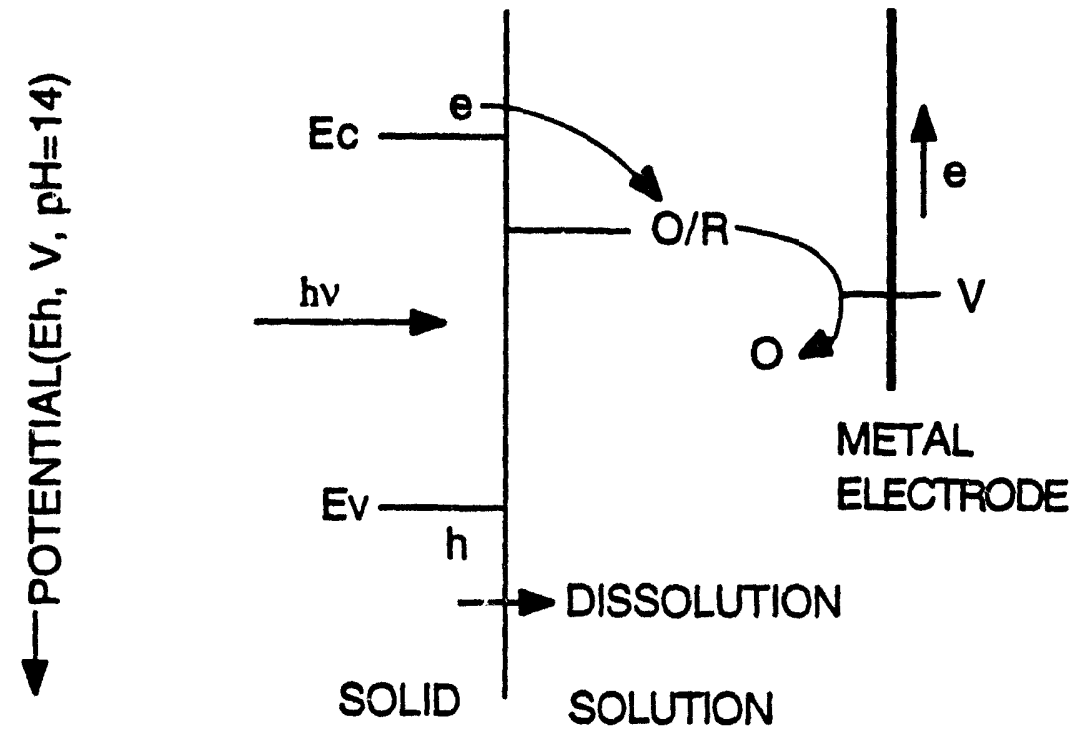

FIGURE 10. Relation of photocurrent and dissolution rate of a semiconductor. 


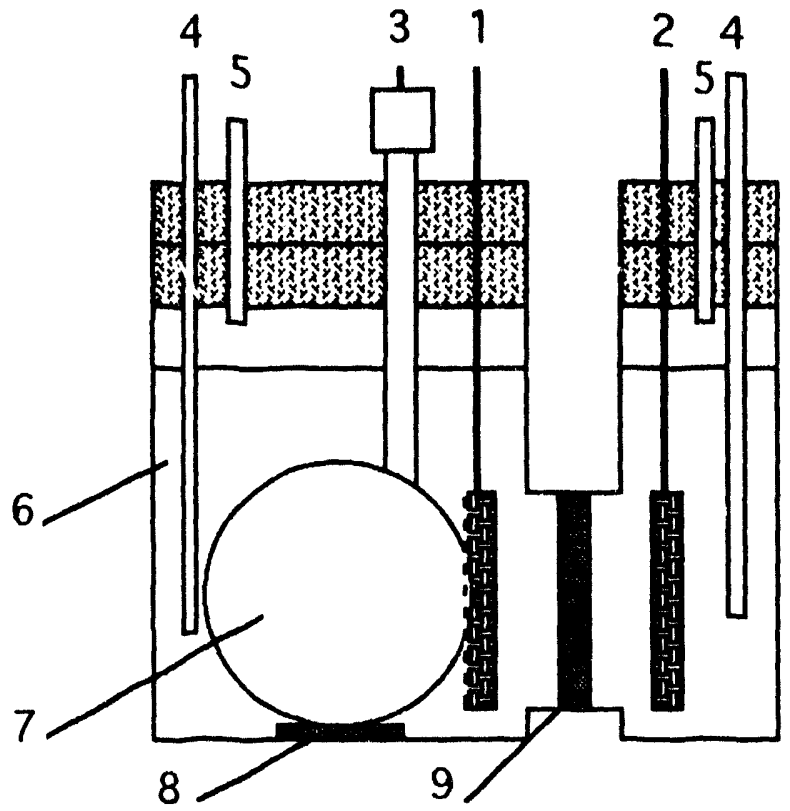

1- working electrode

2- counter electrode

3-reference electrode ( $S C E$ )

4- Nitrogen gas inlet

5- Nitrogen gas outlet

6- main chamber

7- optical window

8- magnetic stirrer

9- glass frit

FIGURE 11 Setup for photoelectrochemical measurements.

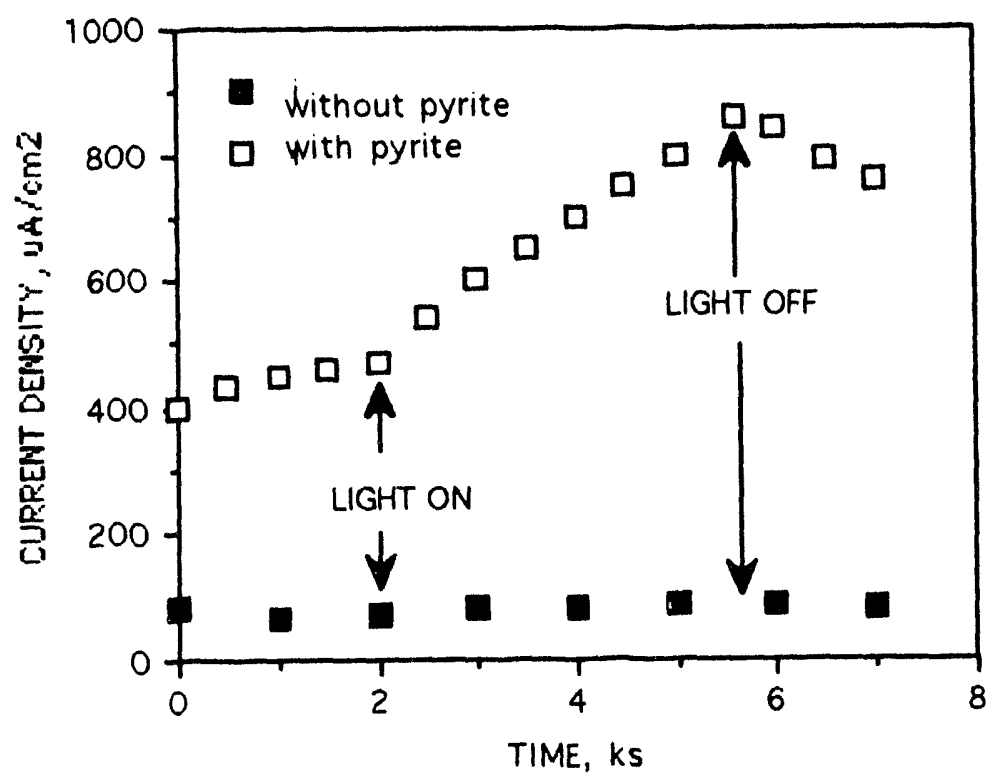

FIGURE 12 Effect of illumination on anodic current with and without pyrite particles. 


\title{
A kinetic and thermodynamic study of the reaction between ferrous and sulfide ions in aqueous solution
}

\author{
Dawei Wei and K. Osseo-Asare \\ Department of Materials Science and Engineering \\ The Pennsylvania State University \\ University Park, PA 16802
}

\begin{abstract}
The kinetics of the reaction between $\mathrm{Fe}(\mathrm{II})$ and $\mathrm{S}(\mathrm{II})$ ions in aqueous solution was investigated by means of the stopped-flow spectrophotometric technique. It was found that an intermediate species, $\mathrm{Fe}(\mathrm{HS})^{2-\mathrm{n}} \mathrm{n}$, formed initially from this reaction and it was subsquently converted to other species. The kinetic experiments showed that the rate of $\mathrm{Fe}(\mathrm{HS})^{2-\mathrm{n}_{\mathrm{n}}}$ formation, for the reaction $\mathrm{Fe}^{2+}+\mathrm{nHS}^{-}=\mathrm{Fe}(\mathrm{HS})^{2-\mathrm{n}_{\mathrm{n}}}$, was first order with respect to both $\mathrm{Fe}^{2+}$ and $\mathrm{HS}^{-}$, and gave a reaction rate constant of $10^{3.81} \mathrm{M}^{-1} \mathrm{sec}^{-1}$. Thermodynamic analysis of the pertinent experimental data also showed that the stoichiometry parameter has a value of 1 and gave an equilibrium constant of $10^{4.34}$ for the reaction: $\mathrm{Fe}^{2+}+\mathrm{HS}^{-}=\mathrm{Fe}(\mathrm{HS})^{+}$. Both the kinetic and thermodynamic results suggest that the intermediate species formed initially from the reaction between $\mathrm{Fe}$ (II) and $\mathrm{S}$ (II) ions is the $1: 1$ complex, $\mathrm{Fe}(\mathrm{HS})^{+}$.
\end{abstract}

Submitted to Geochimica Cosmochimica Acta

December 1993 


\title{
FORMATION OF IRON MONOSULFIDE: A SPECTROPHOTOMETRIC STUDY OF THE REACTION BETWEEN FERROUS AND SULFIDE IONS IN AQUEOUS SOLUTIONS
}

\author{
Dawei Wei and K. Osseo-Asare ${ }^{1}$ \\ Department of Materials Science and Engineering \\ The Pennsylvania State University \\ University Park, PA 16802
}

Submittted to L.Colloid and Interface Science

December 1993.

${ }^{1}$ To whom correspondence should be addressed. 


\begin{abstract}
The reaction between ferrous Fe(II) and sulfide S(II) ions in aqueous solutions was studied by using a stopped-flow spectrophotometric technique. At a wavelength of $500 \mathrm{~nm}$, no absorption was observed with aqueous S(II) solutions, and only limited absorption with Fe(II) solutions. However, when the two different solutions were mixed, a strong absorbance appeared at this wavelength. The absorbance-time curve showed that an intermediate product formed rapidly, within the first few seconds of the reaction; this material subsequently decomposed slowly to other species within the following several minutes. These processes were $\mathrm{pH}$ dependent; it was more likely to form the intermediate in the $\mathrm{pH}$ range from 7 to 8 . This suggests that the reaction between $\mathrm{Fe}^{2+}$ and $\mathrm{HS}^{-}$results in the formation of this species because both $\mathrm{Fe}^{2+}$ and $\mathrm{HS}^{-}$are respectively the predominant $\mathrm{Fe}(\mathrm{II})$ and $\mathrm{S}(\mathrm{II})$ species in this $\mathrm{pH}$ range. The absorbance at $500 \mathrm{~nm}$ varied linearly with the concentration of the intermediate, the absorptivity of which was $4800 \mathrm{M}^{-1} \mathrm{~cm}^{-1}$, as determined in this study. A stoichiometric experiment, by means of the continuous variation method, gave the ratio of $\left[\mathrm{HS}^{-}\right]$to $\left[\mathrm{Fe}^{2+}\right]$ as $1: 1$ for the formation of the intermediate. This shows that the intermediate species was $\mathrm{Fe}(\mathrm{HS})^{+}$. The equilibrium constant for the reaction, $\mathrm{Fe}^{2+}+\mathrm{HS}^{-}=\mathrm{Fe}(\mathrm{HS})^{+}$, was determined as $10^{4.33}$ at $25{ }^{\circ} \mathrm{C}$.
\end{abstract}

\title{
INTRODUCTION
}

The rejection or decomposition of pyrite $\left(\mathrm{FeS}_{2}\right)$ constitutes an essential step in many mineral, metal, and coal processing schemes $(1,2)$. This is because: (a) Pyrite is the most abundant of the metal sulfides found in nature, (b) it is distributed in a wide variety of geochemical settings, and consequently, it is found in association with many mineral and coal deposits $(1,2),(c)$ it is generally considered to be of no commercial value, and (d) it is 
PYRITE IN AQUEOUS SYSTEMS: SEMICONDUCTOR PROPERTIES,

OXIDATIVE DISSOLUTION, AND ENVIRONMENTAL CONTROL*

K. Osseo-Asare

Department of Materials Science and Engineering

The Pennsylvania State University

University Park, PA 16802, USA

\begin{abstract}
The aqueous chemistry of pyrite $\left(\mathrm{FeS}_{2}\right)$ is considered, with emphasis on the relationship between the semiconductor properties of the solid and the characteristics of the interfacial oxidative decorposition reactions. With the aid of energy level correlations which compare the bandedges of pyrite with the energy levels of selected redox couples, the relative importance of valence band holes and conduction band electrons in the corresponding interfacial charge transfer reactions is ascertained. Energy level correlations are also presented which show that the oxidative decomposition of pyrite via a hole pathway is thermodynamically feasible in both acidic and basic solutions. Electrochemical mechanisms are presented which yield rate laws that are consistent with published kinetic data. The upper region of the valence band of pyrite consists of campletely filled iron d-orbitals and these impart catalytic properties to the solid surface. The critical role played in the oxidative decamposition process by the interaction between the surface Fe d-states and $\mathrm{OH}_{2}$ and $\mathrm{OH}^{-}$species in the aqueus phase is highlighted. Implications for environmental control and waste utilization are
\end{abstract} discussed.

*This work was supported by the United States Department of Energy (Grant No. DE-FG22-91 PC91303). The paper was cormpleted during the authors's stay at the Institute for Advanced Materials Processing, Tohoku University, Sendai, Japan. Thanks to Professors $M$. Tokuda and $Y$. Umetsu for providing a supporting environment, and to Dr. S. Uchida for assistance with the preparation of the manuscript.

First Internavonal Conterence on Processing Materials for Propel ues

Edited toy H Henein and T OKI

The Minerais. Metals $\delta$ Materials Sociely, 1993 


\section{INIRODUCTION}

Pyrite $\left(\mathrm{FeS}_{2}\right)$ is the most abundant of the metal sulfides found in nature. It is distributed in a wide variety of geochemical settings, and consequently, it is found in association with many mineral and coal deposits $(1,2)$. Pyrite is generally considered to be of no comercial value, and therefore, the rejection or decamposition of this metal sulfide constitutes an essential component in many mineral, metal, and coal processing flowsheets (2). Recently pyrite has come under active investigation as a potential solar energy material (3), and it has been proposed as an anode depolarizer for electrolytic hydrogen production (4).

In view of its importance in a wide range of natural and technological systems, as summarized in Table 1 , the subject of pyrite oxidation has attracted the attention of investigators from several different flelds, including geochemistry, mining engineering, mineral processing, coal processing, hydro-metallurgy, environmental science and engineering, agronamy, soil science, electrochemistry, electrochemical engineering, materials sclence, and condensed matter physics (1-20). On the one hand, the multi-disciplinary interest in pyrite can be viewed positively: it helps to counteract the tendency of disciplinary blinders to cause the neglect of important aspects of a given problem. On the other hand, the fact that investigators with diverse backgrounds are examining a similar problem can lead, unavoidably perhaps, to the "blind men and the elephant" syndrome. Thus, in one community, papers on pyrite oxidation typically include this refrain: "Pyrite oxidation is a subject of great current interest because of its role in the adverse environmnetal problem of acld mine drainage" $(5,8,9,13)$. However, at the same time, a different group apparently finds no incongruity in promoting its work with a statement such as this: "The pursuit of pyrite as a solar energy material is motivated, in part, by its nontoxicity and environmental friendliness" $(17,20)$.

Table 1 Pyrite oxidation in natural and technological systems

Systens

Supergene-enriched

Mining Wastes

Coal and Mineral Flotation Ore Deposits

Role of Pyrite Oxidation

Generates acid which causes dissolution of metals

whose subsequent reprecipitation produces enriched ores

Causes acid mine drainage

Releases $\mathrm{Fe}$ (II) and $\mathrm{Fe}$ (III) hydroxo species which "activate" the adsorption of flotation reagents on pyrite

Produces a hydrophobic metal-deficient sulfide surface film which promotes collectorless flotation

Produces hydrophilic metal hydroxide and oxide surface film which inhibits flotation

Coal Desulfurization Permits coal desulfurization via chemical leaching

Hydrometallurgical

Processsing

Generates acid used for leaching reactions

Competes with target minerals for oxidants

Raises rest potential; galvanic coupling then accelerates oxidative dissolution of metal sulfides with lower rest potentials

Leads to liberation of gold grains encapsulated in a pyritic matrix

Leads to degradation of solar energy material

Solar Energy Conversion

Electrochemical Hydrogen Prod'n
Provides the anodic reaction coupled to the cathodic generation of hydrogen

Fortunately, the blind men and women can write and read, and also there are many of us. Thus by assembling the available collage of many and different published observations, it may be possible with some patience ana luck to reconstruct the "elephant" hiding behind our multi-farious findings. The purpose of this paper is to contribute to this effort. The focus here is on the relationship between the semiconductor properties of pyrite and the behavior of this metal sulfide in environmentally-relevant aqueous systems. In many cases, the interest in pyrite oxidation derives from the effects of the reaction products (both solid and aqueous) on subsequent natural and indusrial processes. The rate of generation of reaction products and the nature of the reaction products therefore constitute important aspects of the scientific investi-gation of pyrite oxidation. Both aspects of the oxidation process will be considered in this paper, although the emphasis will be on the former, i.e., the rate and mechanism of oxidation. 
The Ionic formula of pyrite is $\mathrm{Fe}^{2+}\left(\mathrm{S}_{2}\right)^{2-}$, and its cubic crystal structure is analogous to that of $\mathrm{NaCl}$ (21). Pyrite is an intrinsic semiconductor; the synthetic material typically exhibits n-type behavior, while both $\mathrm{n}$ - and p-type conductivity have been reported for the natural mineral. The band gap is about 1 ev. The electronic structure is illustrated in Figure 1a $(21,22)$. The energy of the lowest level of the empty orbitals (conduction band) is denoted as $E_{c}$, while the uppermost level of the occupied orbitals (valence band) is represented as $E_{v}(23)$. The interaction of the iron $e_{g}, 4 s$, and $4 p$ orbitals with the hybrid $\mathbf{s p}^{3}$ orbitals of sulfur results in bonding orbitals which give rise to the valence band, and antibonding orbitals which give the conduction band. The enexgy gap $\left(E_{g}\right)$ is represented by the separation between the antibonding $\mathrm{J}^{*}\left(\mathrm{e}_{\mathrm{g}}{ }^{*}\right)$ and nonbonding $t_{2 g}$ orbitals.
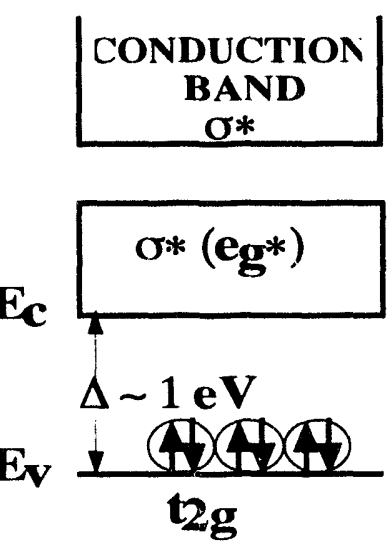

(a)

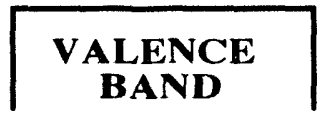

(b)

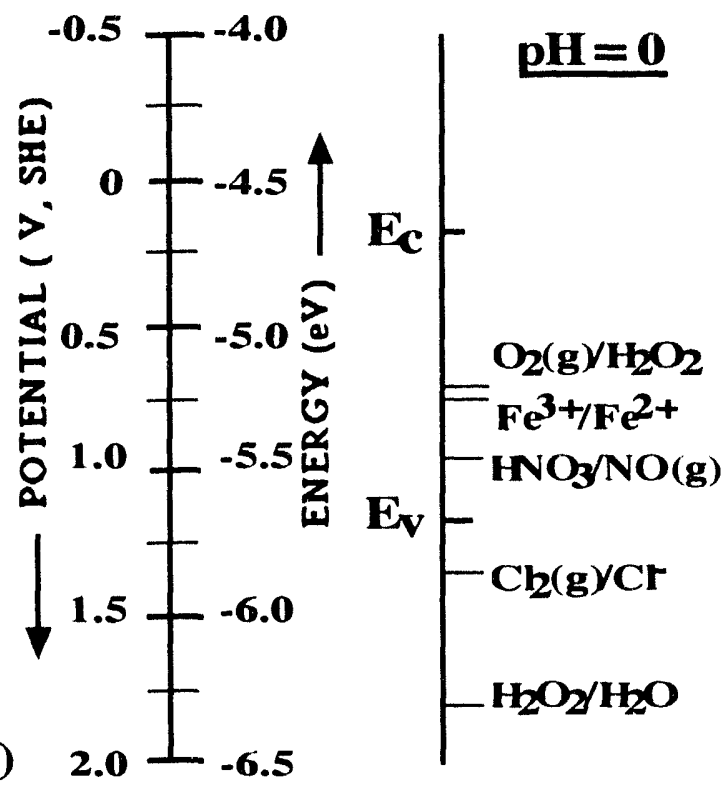

Figure 1. (a) The band model of $\mathrm{FeS}_{2}$. (b) Energy level diagrams illustrating charge transfer between selected redox couples and pyrite; unit activities of aqueous and gaseous redox species.

Energy Level Correlations for Pyrite Oxidation

It is possible to express energy levels ( $\mathrm{E}, \mathrm{eV}$ ) in terms of conventional electrochemical potentials (Eh, v) as $(22,23)$ :

$$
E(e V)=-\operatorname{eEh}(V)-4.5
$$

According to Chen et al. (17), the bandedges of pyrite are given by $E h_{c}=0.14 \mathrm{~V} \mathrm{SHE}\left(-0.1 \mathrm{~V}\right.$ SCE) and $E h_{\mathrm{v}}=$ $1.14 \mathrm{~V}$ SHE $(0.9 \mathrm{~V} \mathrm{SCE})$ at $\mathrm{pH} 0$, and $E h_{c}=-0.66 \mathrm{~V}$ SHE $(-0.9 \mathrm{~V} \mathrm{SCE})$ and $\mathrm{Eh}_{\mathrm{v}}=0.34 \mathrm{~V} \operatorname{SHE}(0.1 \mathrm{~V} \mathrm{SCE})$ at $\mathrm{pH} 14$. With the aid of these and interpolated bandedge values, energy level diagrans (23) can be developed for relevant charge transfer and pyrite decomposition reactions. In Figure $1 \mathrm{~b}$, the bandedges of pyrite are compared with the energy levels (Eredox) of selected redox couples. It can be seen that these redox couples can be divided into two groups, i.e., those which are most likely to interact via conduction band electrons (Eredax $>$ $\left.\mathrm{E}_{\mathrm{y}}: \mathrm{O}_{2} / \mathrm{H}_{2} \mathrm{O}_{2}, \mathrm{Fe}^{3+} / \mathrm{Fe}^{2+}, \mathrm{HNO}_{3} / \mathrm{NO}\right)$ and those which follow the hole injection pathway $\left(\mathrm{E}_{\mathrm{recdax}}<\mathrm{E}_{\mathrm{v}}: \mathrm{Cl}_{2} / \mathrm{Cl}^{-}, \mathrm{H}_{2} \mathrm{O}_{2} / \mathrm{H}_{2} \mathrm{O}\right)$. These trends are in general agreement with those reported by Ahmed and Giziewicz (18).

The electrochenical decomposition of a semiconductor (MX) may proceed either anodically via holes or cathodically via electrons:

$$
\begin{array}{ll}
\mathrm{MX}+\mathrm{zH}^{+}=\mathrm{M}^{\mathrm{z}}+\mathrm{X} & \mathrm{Eh}_{\mathrm{p}} \\
\mathrm{MX}+\mathrm{ze}^{-}=\mathrm{M}+\mathrm{X}^{2-} & E h_{n}
\end{array}
$$

where $E h_{p}$ and $E h_{n}$ respectively represent the reduction potentials associated with the hole (anodic) and electron (cathodic) reactions. If $\mathrm{Eh}_{\mathrm{p}}$ and $\mathrm{Eh}_{\mathrm{n}}$ are converted from the conventional electrochemical potential (SHE) scale to the energy (eV) scale (i.e., $\mathrm{E}_{\mathrm{p}}$ and $\mathrm{E}_{\mathrm{n}}$ respectively; Equation 1), and the Eh imposed on the solid by an applied potential or an oxidant/reductant) is identified with the electrochemical potential of the electrons in the solid (i.e., the energy of the Fermi level of the solid), then the hole-mediated and the electronmediated decampositions will be constrained by Equations 4 and 5 respectively (23): 


$$
\begin{aligned}
& E_{v}<E_{p} \\
& E_{c}>E_{n}
\end{aligned}
$$

Figure 2 illustrates the relationship between the reaction path of pyrite deccmposition (i.e., devcmposition by holes or electrons) and the positions of the energy band edges of the solid. It can be seen that pyrite decomposition by the hole pathway is feasible in both acidic and basic solution, whereas the electron pathway to $\mathrm{Fe}^{2+}$ and $\mathrm{HS}^{-}$is not feasible in basic solution.

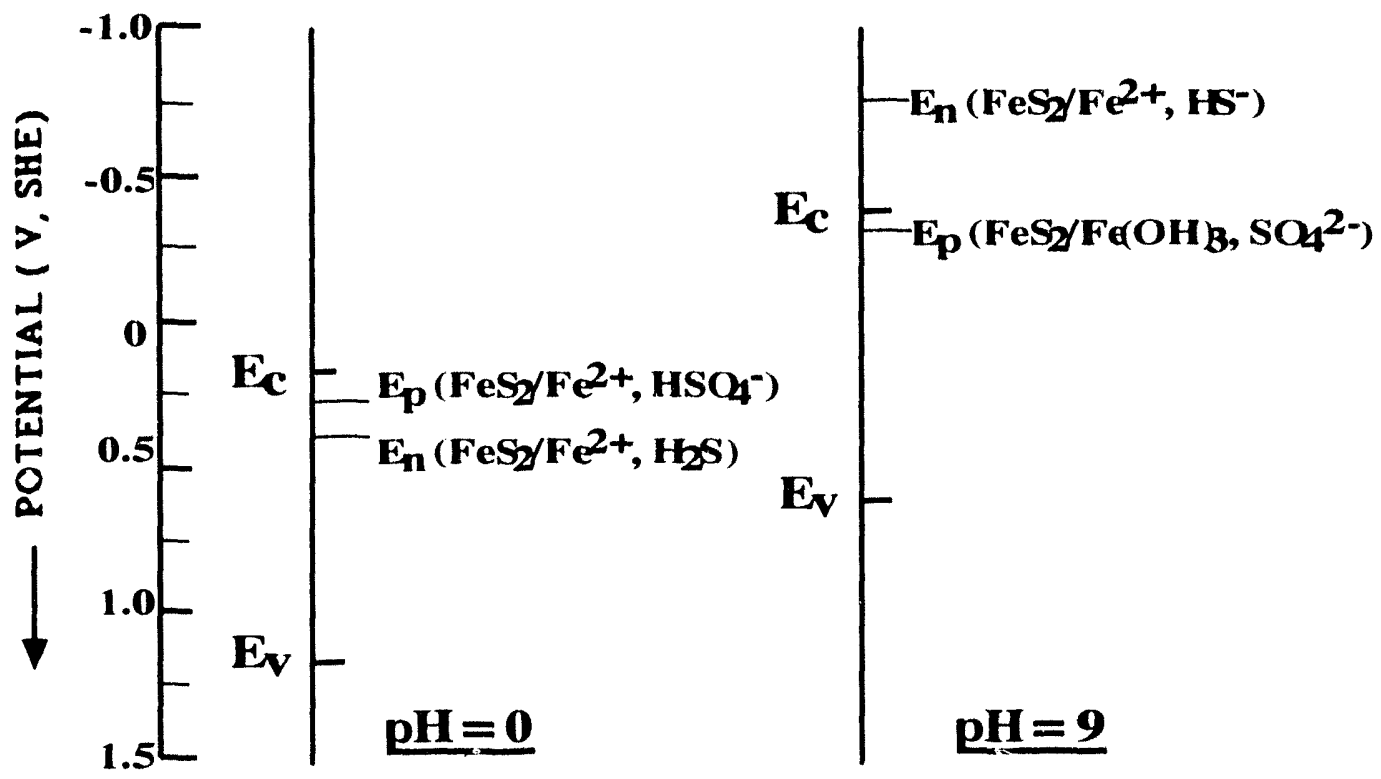

Figure 2. Correlation between decarposition potentials and the energy bands of pyrite; aqueous iron and sulfur species at $0.001 \mathrm{M}$ concentrations (activities).

Regarding oxidative decomposition, the question now arises: How are the necessary holes provided? In approaching this question, it is helpful to recognize that for semiconductors with relatively low bandgaps, thermal agitation can lead to the creation of electron-hole pairs (Figure 3a); the concentration of these electron-hole pairs may be increased by irradiation $(22,23)$. These pairs will generally recombine; however, if a reagent is available at the solid/water interface which can capture the electron sufficiently rapidly, recombination will be avoided, and the resulting hole will be available to participate in the decamposition reaction (Figure $3 \mathrm{~b}$ ). In another scenario, a sufficiently strong oxidant in the aqueous phase may extract electrons fram the valence band; this can be viewed as the injection of holes into the valence band (Figure $3 c)$.

(a)

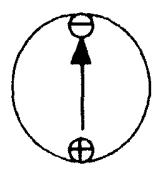

(b)

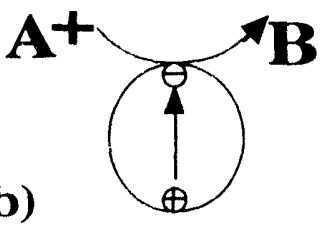

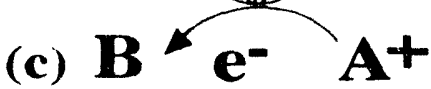

Figure 3. Generation and separation of electron-hole pairs: (a) Generation of electron-hole pairs by thermal agitation and/or irradiation, (b) electron capture by aqueous species, (c) hole injection by aqueous species.

\section{EIECIROCHEMICAL RERCTIONS AND RATE LAWS FOR OXIDATTVE DISSOLUTION}

\section{Iron d-States and Pyrite Decomposition}

Metal sulfides photocorrode to give sulfate ions or elemental sulfur, depending on whether they are dband or non-d-band semiconductors (3). In the case of a d-band semiconductor, such as pyrite, the uppermost region of the valence band consists of metal nonbonding $t_{2 g}$ orbitals (see Figure 1a). Thus the creation of a hole in the valence band merely transforms $\mathrm{Fe}^{2+}$ to $\mathrm{Fe}^{3+}$; no metal-sulfur bonds are broken. In contrast, for a non-d-band semiconductor, such as $\mathrm{2nS}$, the upper layer of the valence band consists of molecular orbitals created from a combination of $s$ and $p$ orbitals of zinc and sulfur. In this case, the holes break bonding orbitals and lead to elemental sulfur formation.

How then does pyrite decampose? The initial stages of pyrite oxidation appear to parallel the electroadsorption of $\mathrm{H}_{2} \mathrm{O}$ molecules and $\mathrm{OH}^{-}$ions on metal surfaces $(3,16)$. In analogy with metal electrodes 
(24), and with supporting data from electrochemical polarization experiments, Equation 6 was suggested (16) as the first step in the surface oxidation of pyrite in acidic solutions. Equation 7 gives the corresponding expression for reaction in basic solution.

$$
\begin{aligned}
& \mathrm{FeS}_{2}+\mathrm{H}_{2} \mathrm{O} \rightarrow \mathrm{Fe}(\mathrm{OH}) \mathrm{S}_{2}+\mathrm{H}^{+}+\mathrm{e}^{-} \\
& \mathrm{FeS}_{2}+\mathrm{OH}^{-} \rightarrow \mathrm{Fe}(\mathrm{OH}) \mathrm{S}_{2}+\mathrm{e}^{-}
\end{aligned}
$$

The pyrite surface catalyzes these reactions through the strong interaction of iron $3 d$ orbitals with $\mathrm{OH}_{2}$ molecules and $\mathrm{OH}^{-}$lons (Tributsch). The $\mathrm{OH}$ radicals subsequently migrate to $\mathrm{S}_{2}^{2-}$ sites where they react to give (eventually) sulfate tons:

$$
\begin{aligned}
& \mathrm{Fe}(\mathrm{OH}) \mathrm{S}_{2}=\mathrm{FeS}_{2}(\mathrm{OH}) \\
& \mathrm{FeS}_{2}(\mathrm{OH})+2 \mathrm{H}_{2} \mathrm{O}=\mathrm{Fe}^{2+}+\mathrm{S}_{2} \mathrm{O}^{2-}+\mathrm{H}^{+}+5 e^{-}
\end{aligned}
$$

The surface thiosulfate subsequently decompes to give elemental sulfur and a bisulfite Ion (Equation 10); the $\mathrm{HSO}_{3}{ }^{-}$and additional $\mathrm{S}_{2} \mathrm{O}_{3}{ }^{2-}$ ions then undergo further oxidation to sulfate ions.

$$
\mathrm{S}_{2} \mathrm{O}_{3}^{2-}+\mathrm{H}^{+} \rightarrow \mathrm{S}+\mathrm{HSO}_{3}^{-}
$$

Derivation of Rate Laws from Reaction Mechanisms

A number of molecular mechanisms of pyrite oxidation have been presented in the literature $(1,2)$. Unfortunately, little attempt has been made to reconcile the proposed mechanisans with the experimentally observed rate laws. As discussed in detail elsewhere (25), reasonable electrochenical mechanisms can be proposed which can lead to rate laws that are compatible with the reported reaction orders for pyrite dissolution. Consider the oxidative decomposition of pyrite in the presence of an oxidant $\mathrm{A}^{+}$. From an electrochenical standpoint, the obser nd dissolution takes place at a mixed potential, Em, such that the magnitude of the overall cathodic cur. nt (i.e., rate) equals that of the overall anodic current. Let the overall cathodic reaction be controlled oy the following electron transfei step:

$$
\mathrm{A}^{+}+\mathrm{e}^{-} \rightarrow \mathrm{B}
$$

Suppose the rate of the overall anodic reaction is controlled by Equations 6 and 7 in acidic and basic solutions respectively. Then it can be shown (25), using the Butler-Volmer equations (26) that for an irreversible oxidative acid dissolution reaction where $\left[A^{+}\right] \gg[B]$, the dissolution current $(1 . e .$, rate) is given by:

$$
\begin{aligned}
& i=k_{1}\left[\mathrm{~A}^{+}\right]^{\phi} \\
& i=k_{2}\left[\mathrm{OH}^{-}\right]^{\Phi}\left[\mathrm{A}^{+}\right]^{\Phi}
\end{aligned}
$$$$
\text { (Acidic solution) }
$$$$
\text { (Basic solution) }
$$

where the $k$ parameters represent rate constants, $F$ is the Faraday constant, $\phi=\left(u_{b} /\left(1+c_{c}-\left(c_{c}\right)\right.\right.$, and $c_{b}$ and $u_{c}$ respectively are the transfer coefficients for the overall anodic and cathodic reactions (26). Typically the value of a transfer coefficient is -0.5 ; therefore $\phi-0.5$, which is the reaction order of both $\mathrm{A}^{+}$and $\mathrm{OH}^{-}$in the above rate equations.

Based on the available information on the corresponding reactions on metal surfaces (24), the rate detemining steps for the cathodic reactions (involving $\mathrm{Fe}^{3+}, \mathrm{O}_{2}$, and $\mathrm{H}_{2} \mathrm{O}_{2}$ ) on pyrite surface can be proposed as:

$$
\begin{aligned}
& \mathrm{Fe}^{3+}+\mathrm{e}^{-} \rightarrow \mathrm{Fe}^{2+} \\
& \mathrm{O}_{2}+\mathrm{e}^{-} \rightarrow \mathrm{O}^{2-} \\
& \mathrm{H}_{2} \mathrm{O}_{2} \rightarrow 2 \mathrm{OH}
\end{aligned}
$$

In the light of these rate determining steps and Equations 12 and 13 , the relevant reaction orders are (25): 0.5 for $\mathrm{Fe}^{3+}, 0.5$ for $\mathrm{O}_{2}, 0.5$ for $\mathrm{OH}^{-}$, and 1.0 for $\mathrm{H}_{2} \mathrm{O}_{3}$. These trends are consistent with the reaction orders reported in the pyrite dissolution literature, as summarized by Mckibben and Barnes (6), and also with the recent rate laws reported by Ciminelli (15) for pyrite oxidation in basic solutions.

\section{SEMICONDUCTOR PROPERTIES, PYRTTE OXIDATION, AND THE ENVIRONMENT}

Inhibition and Enhancement of Pyrite Oxidation

When considering either the inhibition or enhancement of pyrite decomposition, it is crucial to keep in mind the catalytic properties of iron-d-states, particularly the critical role played by the interaction between $\mathrm{Fe}$ sites on the pyrite surface and $\mathrm{OH}_{2}$ molecules and $\mathrm{OH}^{-}$tons in the aqueous phase $(3,16)$. This interaction constitutes the first step in the successive reactions that lead eventually to the decomposition of the solid. Accordingly, if the object is to discourage pyrite dissolution (e.g. as in the abatement of acid mine drainage), then a reasonable strategy is to search for species that can cormete successfully with $\mathrm{OH}_{2}$ molecules and $\mathrm{OH}^{-}$ions for the adsorption sites. On the other hand, where the goal is to enhance pyrite decomposition (e.g., as in coal desulfurization by chemical leaching, and the oxidative pretreatment of 
refractory pyritic gold ores), a possible approach is to create conditions that favor the interaction of $\mathrm{H}_{2} \mathrm{O}$ and of with the solid surface.

Regarding the inhibition of pyrite decamposition, it must be recognized that following risorption, a species B may: (a) form soluble complexes with $\mathrm{Fe}^{2+}$ and/or $\mathrm{Fe}^{3+}$, (b) undergo an electron transfer reaction (1.e., oxidation), or (c) form insoluble complexes with $\mathrm{Fe}^{2+}$ and/or $\mathrm{Fe}^{3+}$. By enhancing pyrite solubility, case (a) may actually aggravate the situation. With case (b), B acts as a sacrificial electron donor (or hole acceptor) and will stabilize pyrite against decamposition, so long as its concentration is maintained at a sufficiently high level. Case (C) can be expected to provide long term protection against pyrite decamposition, provided an adhering nonporous $\mathrm{fllm}$ forms. These ideas are supported by experimental studies on the effects of various reagents on pyrite oxidation (13), and by the results of photoelectrochemical investigations on the pyrite surface $(3,17,20)$. Thus, Chander and zhou (13) found from their accelerated weathering column experiments that organic reagents with di-hydroxy groups depressed, while those with dicarboxy1 groupe enhanced pyrite decamposition. Apparently the hydroxylic reagents formed insoluble surface chelates with iron, whereas the carboxylic compounds gave aqueous-soluble iron camplexes. It has been reported by Tributsch et al. $(3,20)$ that photogenerated holes oxidize hallde lons $\left(\mathrm{Cl}^{-}, \mathrm{Br}^{-}, \mathrm{I}^{-}\right)$to the mlecular halogens on pyrite electrodes, and that this stabilizes the electrodes against photocorrosion. Cinen et al. (17) also found that the tartrate ion is an efficlent scavenger of photogenerated holes at the pyrite/aqueous interface, being oxidized to $\mathrm{CO}_{2}$.

The scenario outlined above for reagent $B$ also applies to the hydroxyl ion. Thus, depending on the pH and $\mathrm{Eh}$, the adsorbed hydroxyl Ion may: (a) form soluble hydroxo carplexes with $\mathrm{Fe}^{2+}$ and $\mathrm{Fe}^{3+}$ ions, (b) undergo electron transfer to produce the of radical which eventually oxidizes the lattloe disulfide ions, and (c) form insoluble hydrous oxides with $\mathrm{Fe}^{2+}$ and $\mathrm{Fe}^{3+}$ ions. Basic solutions favor the formation of gurface oxides on pyrite and the possibility of exploiting such filims as oxidation barriers has been considered. However, these attempts have not been successful $(8,9,13,18)$. A possible reason is that of radical formation (case (b)) and oxics formation (case (c)) are both favored by high ph. A common approach to the acid mine drainage problem is to apply limestone, in an effort to maintain a basic pH. Here an additional factor contributing to the inability to effect long term pyrite stabilization might be the formation of soluble Fe(II) and Fe(III) carbonate complexes. Ciminelli (15) found that for the same pH, pyrite dissolution with molecular oxygen was faster in $\mathrm{Na}_{2} \mathrm{CO}_{3}$ solution than in $\mathrm{NaOH}$ solution; the formation of soluble $\mathrm{Fe}$ (II) and Fe(III) carbonate carmplexes probably contributes to the observed trend.

Semiconductor Properties, Waste Treatment, and Waste Utilization

Given its ubiquitous association with valued metals in mineral deposits worldwide, and our insatlable need for new materials and energy, it is likely that into the foreseable future, pyrite wastes will continue to pose a serious threat to the environment. An intriguing notion is the possibility that this enemy of the environment and process technology may be exploited in the service of the environment. Same guidance regarding possible approaches is provided by the available experimental results which demonstrate that: (a) pyrite can be used as an anode depolarizer for the electrolytic production of hydrogen fram water (4), (b) the photoactive properties of pyrite permit the conversion of solar energy into chemical or electrical energy $(3,17,20)$, and (c) aqueous suspensions of semiconductor particles (e.g. titania) can be used as photocatalysts in the destruction of both organic and inorganic pollutants (e.g., cyanide) (27). Working out the details of these new possibilities constitutes a challenge for current and future pyriterians.

\section{REFERENCES}

1. J. B. Hiskey and W. J. Schlitt, "Aqueous Oxidation of Pyrite", in Interfacing Technologiegin Solution Mining, ed., W. J. Schlitt and J. B. Hiskey (Littleton, CO: SME, 1982) 55-74.

2. D. K. Nordstram, "Aqueous Pyrite Oxidation and the Consequent Formation of Secondary Iron Minerals", in Acid Surface Weathering, ed. J. A. Kittrick, D. S. Fanning, and L. R. Hossner (Madison, WIs Soil Sci Soc. Amer., 1982) 37-56.

3. H. Tributsch, "Photoelectrolysis and Photoelectrochemical Catalysis", in Modern Aspects of Electrochenistry, Vol. 17, ed. J. O'M. Bockris, B. E. Conway, ind R. E. White (New York, NY: Plenum, 1986) 303355.

4. S. B. Lalvani and M. Shami, "Elec rochemical Oxidation of Pyrite Slurries", I. Electrochem. Soc., 133 (1968) 1364-1368.

5. R. T. Lowson, "Aqueous Oxidation of Pyrite by Molecular Oxygen", Chen. Rey., 82 (1982) $461-497$.

6. M. A. McKibben and H. L. Barnes, "Oxidation of Pyrite in Low Temperature Acidic Solutions: Rate Laws and Surface Tectures", Geochim. Cosmochim. Acta, 50 (1986) 1509-1520.

7. G. W. Luther, III, "Pyrite Oxidation and Reductions Molecular Orbital Theory Considerations", Geochimica et Cosmochimica Acta, 51 (1987) 3193-3199.

8. R. V. Nicholson, R. W. Gillham, and E. J. Reardon, "Pyrite Oxidation in Carbonate-buffered solution: 2. Rate Control by Oxide Coatings", Geochim, Cosmochim. Acta, 54 (1990) 395-402.

9. C. O. Moses and J. S. Herman, "Pyrite Oxidation at Circumneutral pH", Geochim. Cosmochim. Acta, 55 (1991) 471-482. 
10. A. N. Buckley and R. Woods, "The Surface Oxidation of Pyrite", Apole Surf. Sche, 27 (1987) 437-452.12. E. Ahlberg, E. Forsaberg, and $X$. Wang, "The Surface Oxidation of Pyrite in Alkaline Solution", J. Apol, Electrochem., 20 (1990) 1033-1039.

11. X. Zhu, J. LI, D. M. Bodily, and M. E. Wadeworth, "manspassive Oxidation of Pyrite", in Electrochemistiry In Mineral and Metal Preceseing III, ed., R. Woods and P. E. Richardson (Pennington, NJ, The Electrochemical Society, 1992), 391-409.

12. S. Chander and A. Briceno, "Kinetics of Pyrite Oxidation", Miner. Metal1. Proc., 4 (1987) 171-176.

13. S. Chander and R. Zhou, "Effect of Organic Additives on Acid Generation fran Pyrite Waste", in Bmeraing Procese Trohnelegtes for a Cleaver Bnviroment, ed.,S. Chander, P. E. Richardson, and H. El-Shall (Littleton, CO: SME, 1992), 131-139.

14. L. K. Balley and E. Peters, "Decomposition of Pyrite in Acids by Pressure Leaching and Anodization: The Case for an Electrochemical Mechanlam", Canad. Met. Quart. 15 (1976) 333-344.

15. V. S. T. Ciminell: and K. Osseo-Asare, "Kinetics of Pyrite Oxidation in Sodium Carbonate Solution", Metall, Trans. B (subandtted).

16. K. K. Mishra and K. Osseo-Asare, "Aspects of the Interfaclal Electrochemistry of Semiconductor Pyrite $\left(\mathrm{FeS}_{2}\right) "$, J. Flectro hem. Socer 135 (1988) 2502-2509.

17. G. Chen, J. M. Zen, F. R. F. Fan, and A. J. Bard, "Electrochemical Invegtigation of the Energetics of Irradiated FeS, (Pyrite) Particles", J. Phys. Chem., 95 (1991) 3682-3687.

18. S. M. Ahmed and E. Gizlewicz, "Electrochemical Studias of Iron Sulfides in Relation to their Atmospheric Oxidation and Prevention of Acid Drainage; Part-II", in Electrochemigtry in Mineral and Metal Processing III, ed., R. Woods and P. E. Richardson (Pennington, NJ: The Electrochemical Soclety, 1992), 372-390.

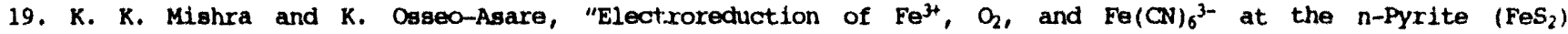
Surface", J. Electrochem. Soce, 139 (1992) 3115-3120

20. A. Ennaoul, S. Fiechter, H. Tributgch, M. Giersig, R. Vogel, and H. Weller, "Photochemical Energy Conversion Obtained with Ultrathin Organo-Metallic-Chemical-Vapor-Depositioon of Fes (Pyrite) on TiO ${ }_{2}$. $\mathrm{J}_{2}$ Electrochem. Soc. , 139 (1992) 2514-2518.

21. D. J. Vaughan and J. R. Craig, Mineral Chemigtry of Metal Sulfideg (New York, NY: Cambridge, 1978).

22. K. Osseo-Asare, "Semiconductor Electroctemistry and Hydrometallurgical Dissolution Processes", Hydrametallurgy, 25 (1992) 61-90.

23. S. R. Morrison, Electrochemistry at Semiconductor and Oxidized Metal Electrodes (New York, NY, Plenum, $1980)$.

24. A. Damjanovic, "Mechanistic Analysis of Oxygen Electrode Reactions", in Medern Abpects of Electrochemistry, Vol. 5, ed. J. O'M. Bockris and B. E. Cone ray (New York, NY, Plenum, 1969) 369-483.

25. K. Osseo-Asare, "Kinetics and Mechanisms of Pyrite Oxidation in Aqueous Solutions: Electrochemical Models", in preparation.

26. M. E. Wadsworth, "Heterogeneous Rate Processes in the Leaching of Base Metal Sulfides", in Hydrometallurgical Process Fundamentals, ed., R. G. Bautista (New York, NY: Plenum, 1984 ) $41-76$.

27. S. Frank and A. Bard, "Heterogeneous Photocatalytic Oxidation of Cyanide Ion in Aqueous Solutions at TiO Powder", J. Am. Chen. Soc. 99 (1977) 303-304. 

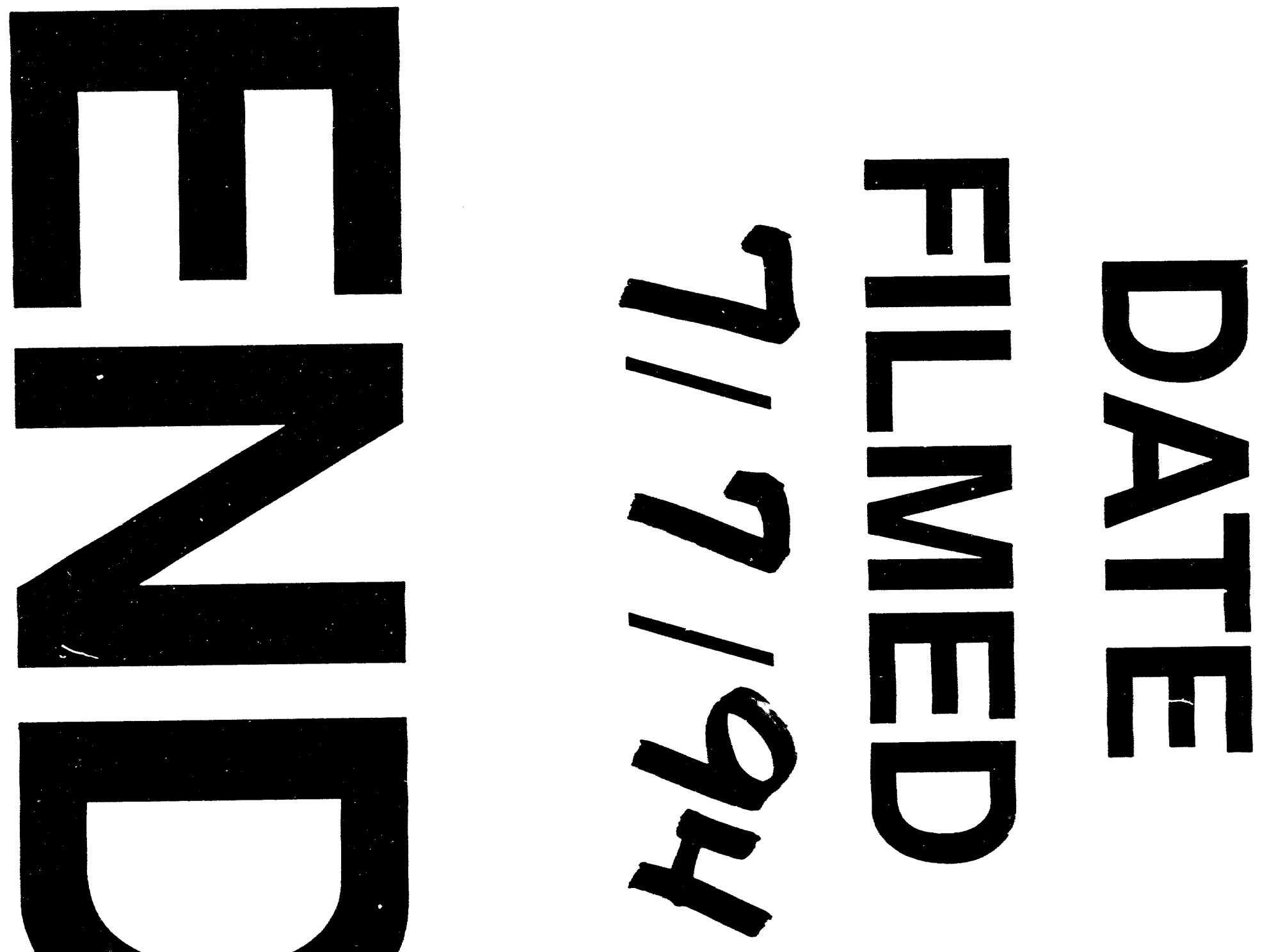

$\Sigma$

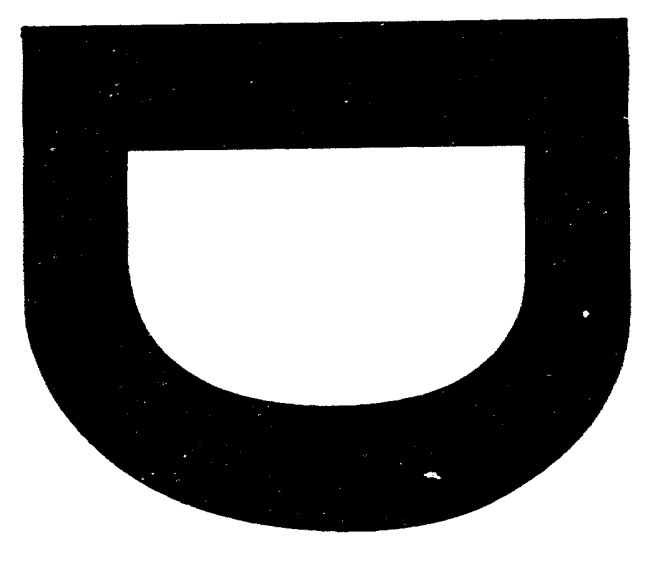



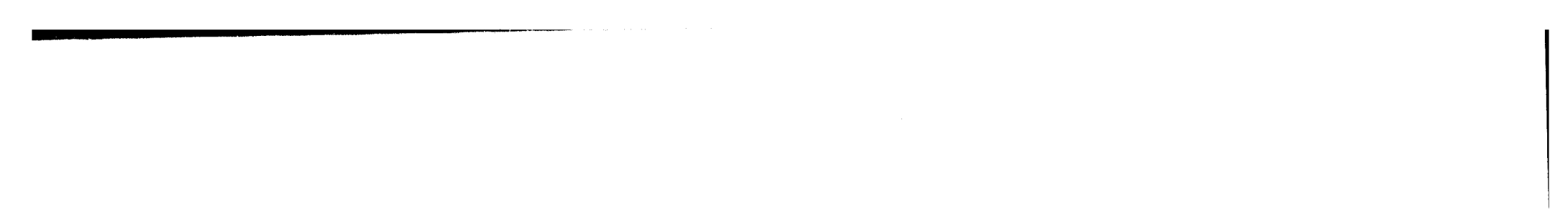